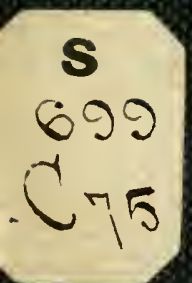

80 


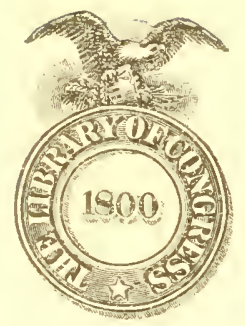

Class

Book

Copyright No.

COPYRIGIT DEPOSIT. 






\title{
THE SCIENCE
}

\author{
OF
}

THRESHING.

BY

G. F. COnner.

13892

PRICE \$1.00. S(6.26.189)

PUBLISHED BY

THE UNION COMPANY

RACINE, WIS. 
Copyright, G F. CONNER, 1897.

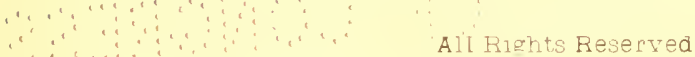




\section{PREFACE.}

] short a time as the present generation has witnessed in grain handling machinery.

When we consider the difficulties to be encountered and the obstacles to overcome in taking the minute kernels, husking them from the chaff in which nature has enveloped them, depositing the golden grain in the sack, delivering the refuse at the Operator's command in so perfect and expeditious a manner, we may look upon the modern thresher as a marvel of success.

To the Thresherman in the field belongs more credit for this achievement than is generally accredited him. He is the final dictator. On his judgement must a device stand or fall. His part to suggest, the Manufacturer's to execute. Still there is room for more and deeper study. Further progress can be made by all working in unison.

If this book is the means of aiding any one in his part of the work, the author will feel conscious of being well repaid for the labor and time used in preparing it.

Due acknowledgement is extended to all who have aided in any way to make it a success.

RaCINE, WIS., I 897 .

G. F. C.

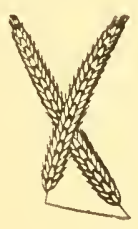





\section{Contents.}

I.AGK.

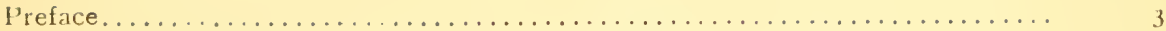

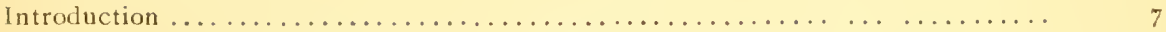

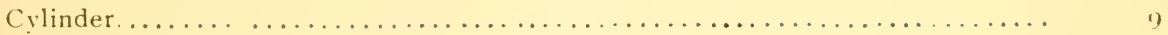

Concaves............................................ I 2

Feed Board $\ldots \ldots \ldots \ldots \ldots \ldots \ldots \ldots \ldots \ldots \ldots \ldots \ldots \ldots \ldots \ldots \ldots \ldots \ldots \ldots \ldots \ldots$

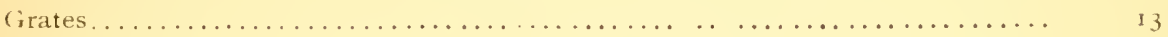

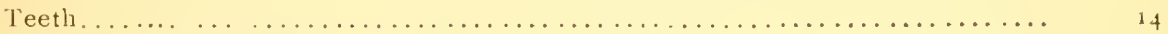

Beater......................................... $\ldots$

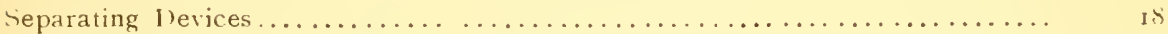

The shoe ....................................... 22

Separator Cuts ..................................... 270

Self Feeders....................................... 52

Feeder Cuts ...................................... $54-5$,

Feeding . . . . . . . . . . . . . . . . . . . . . . . . . . .

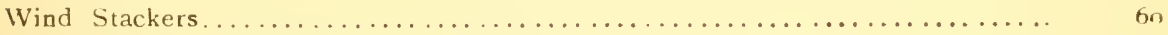

Handling the Threshed Grain ................................. or

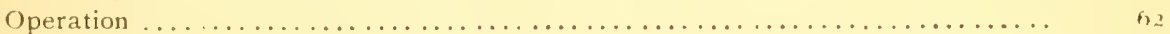

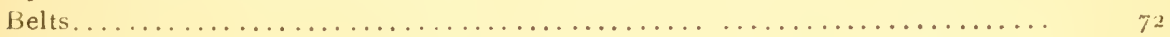

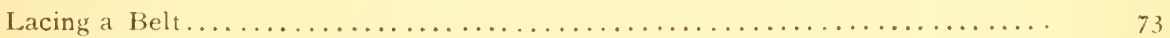

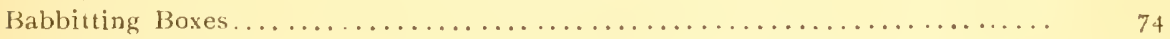

Lubrication . . . . . . . . . . . . . . . . . . . . . . . . . .

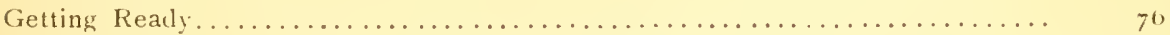

The Crew ............................................

The Engine $\ldots \ldots \ldots \ldots \ldots \ldots \ldots \ldots \ldots \ldots \ldots \ldots \ldots \ldots \ldots \ldots \ldots \ldots \ldots \ldots$

Setting the 1 achine $\ldots \ldots \ldots \ldots \ldots \ldots \ldots \ldots \ldots \ldots \ldots \ldots \ldots \ldots \ldots \ldots$

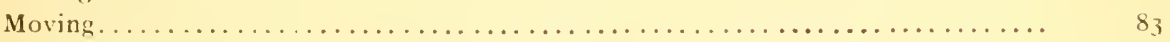

Wasting Grain . . . . . . . . . . . . . . . . . . . . . . . . . . . . $8_{4}$

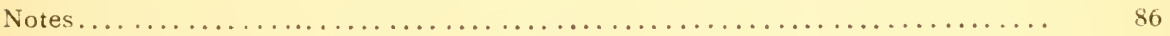

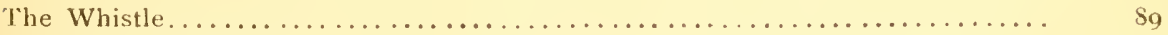

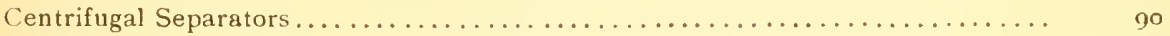

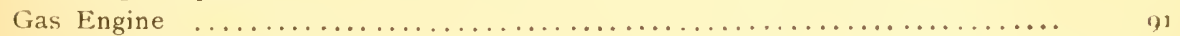

How to Become an Expert.....................................

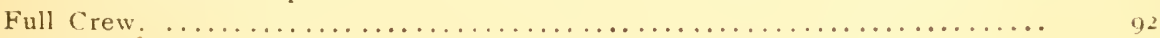

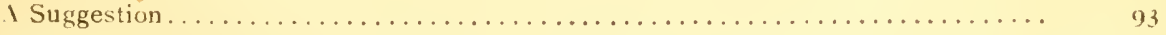

Tables............................................ $94-97$

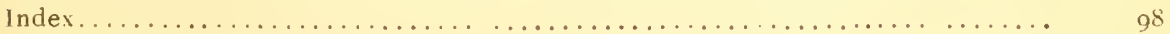





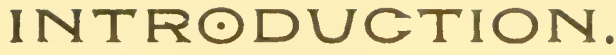

The position is taken by some that there can be no definite rule formulated by which to operate a machine, which may be true to a certain extent. The same may be said with equal truthfulness of any work requiring skill, as skill can only be had by experience. The mind must first be informed and then the hands made skillful. The mind will grasp information from any source within reach.

Each and every part of a machine from the foot-board of the engine to the tail end of the straw carrier, works under and obeys some law peculiar to itself, and unless both manufacturer and operator understand these various laws and principles, the device is liable to fail to perform the functions intended, though both may have had unlimited experience. The written rule is much the better method by which to gain a knowledge of the law.

This knowledge can be put in practice much easier and more successfully than by depending on the slow process of the school of experience to educate the head and teach what should have been understood at the beginning. 

If permitted to run so, it will have a tendency to cause the cylinder boxes to heat and wear out much more rapidly, and also has a tendency to flatten the cylinder shaft on the side that receives the wearing strain. A smoothly running cylinder requires much less power to drive it; as whatever force it takes to cause the vibration is so much power lost, besides interfering with the working and lasting qualities of the machine. Excessive vibration has a tendency to loosen the frame work of the entire machine.

A cylinder may be put in balance by removing it and placing it on two straight edges set up edgewise to receive the journals of the cylinder shaft. The squares or straight edges should first be trued up with a spirit level and may be held in position on edge by driving spikes on either side. The cylinder will adjust itself by turning on the straight edges, the heavier side going down. IVedges, or pieces of iron of sufficient weight, should be driven in between the band and head on the light or upper side of the cylinder to cause it to balance or remain without turning in any position in which it may be placed.

If cylinders are properly balanced when they come from the shop this method will usually put them in good working order. However, a cylinder may indicate to be in perfect balance on the straight edges but in motion in the machine not so, the cause being that one end is heavier on one side while the other end of the cylinder is correspondingly heavy on the opposite side, thus preventing the straight edges from indicating which is the heavier side. In such case the cylinder should be revolved at a rapid speed in loose boxes, and while in motion a piece of chalk held stationary near enough to the shaft at the journal to slightly mark it. This will indicate the light side and a balancing piece should be inserted as before. Both ends should be trued in the same manner.

A cylinder is sometimes thrown out of balance by putting in part new teeth, leaving a part of the worn ones in and not having them evenly distributed around the cylinder. In this case the remedy is to put in all new teeth where they are much worn.

The office of a cylinder is to loosen the kernels from the straw. This is accomplished by the cylinder tooth striking the unthreshed head with sufficient force to jar the kernels loose from the chaff. The cylinder should be run with sufficient speed to entirely free all the ker- 
nels, and not leave any in the straw. If for any reason the cylinder does not do its work thoroughly, the result is the wasting of grain. In some instances some of the kernels will be partially loosened, but adhere to the head until nearly through the machine when they will fall out and be carried along with the straw to the straw stack, thus making the machine appear to be at fault in separation in wasting the grain. The usual speed of an ordinary cylinder is from IO50 to II 50 revolutions per minute. This gives a speed to the teeth of about 6,000 feet per minute. Under ordinary circumstances this will thoroughly dislodge the kernels, if the tooth is brought in contact with the head in a proper manner.

The cylinder boxes should be adjusted endwise so as to bring the cylinder teeth midway between the concave teeth and prevent the cylinder from having end play.

It will greatly aid the cylinder in working freely and easily to have the separator stand still on its trucks while in operation for the reason that the cylinder is a gyroscope on a large scale. Or, in other words it consumes and takes more power to vibrate and move the cylinder back and forth while in rapid motion than if the cylinder did not revolve, and it also requires more power to revolve the cylinder while vibrating.

This principle or law is but slightly understood and difficult to explain. Though any one may take the little toy called the gyroscope and easily demonstrate the fact. While it is revolving rapidly, grasp the frame and move it quickly back and forth. It can be plainly felt to resist the movement with a marked degree of force, and will come to rest much quicker in its rotary motion while being oscillated than if the journals are allowed to remain at rest, clearly showing that a part of the force is consumed in the resistance before mentioned. It is then reasonable to suppose that the cylinder being so much heavier will consume a correspondingly large amount of power to cause it to oscillate while in so rapid motion. It has been demonstrated by actual test that a separator will run much easier while standing perfectly quiet and still than if permitted to rock back and forth on its trucks. 


\section{Concaves.}

Concaves should be sufficiently strong to stand the enormous strain they are subjected to in "slugging" or threshing damp grain. Care should be used to see that none of the teeth are too long to permit the concave being raised to its full height without striking. There should be stops provided to keep the concave from raising too high at either end. These should be adjusted to allow it to be raised as high as possible without striking the teeth. It is good practice to use the concave set clear up and use less rows of teeth, rather than to use more teeth and lower the concave. In the latter case it leaves a space below the points of cylinder teeth to permit whole heads to pass without being acted upon sufficiently to shell the kernels out. When the work will permit, remove one or more of the concaves and insert blanks without teeth. However in some cases where the straw is very dry and brittle and inclined to break up badly, the concave may be lowered a little to advantage. Some are constructed to adjust both rear and front. It is contended by some that a cylinder is less liable to "slug" when the concave is lowered in the rear and raised in front than when up in the rear and down in front, on account of the wedge shaped angle presented for the straw to enter.

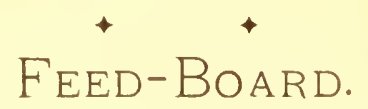

In hand-feeding the tables and feed-board should be kept smooth and free from nails to facilitate the moving of the straw. If the cylinder does not have draft enough, or take the straw free enough, it may be helped by rounding or curving the lower edge of the feed-board that comes in contact with the concave. The straw will pass over this rounded portion more freely than it would pass the sharp angle, and be broken or cut up less, a desirable point to be gained.

It is good practice to keep the lower edge of the feed-board on top of the concave, close to the cylinder teeth even when the concave is lowered somewhat. Then every head will be acted upon by the cylinder teeth as it enters, otherwise it might pass along close to the bottom of the concave unthreshed. 


\section{Grates.}

The grates back of the concave are very essential to assist in separation, if the spaces between the grates are of sufficient width to freely permit flying kernels to fall through. The adjustment should be such that the straw passing from the concave will strike the surface of the grate at a slight angle; this will assist in the separation by directing the kernels through it. The action of the passing straw will also tend to keep the grate clean, and prevent it from loading up with chaff and sticks. 


\section{TEETH.}

The cylinder teeth should pass midway between the concave teeth. Any bent ones may be straightened with a heavy hammer, and the cylinder boxes adjusted edgewise to make all the teeth run squarely in the center. If permitted to have too much end play or run too close together it will cause cracking of the grain and chop the straw up too much; besides it may leave a correspondingly large opening at one side of the tooth that will permit heads of grain to pass unthreshed.

The teeth shell the kernels from the head by striking them with such force as to jar them loose. The concave teeth are for the purpose of retarding the speed of the straw while receiving the action of the cylinder teeth. Only enough concave teeth should be used to hold the straw until threshed clean, as more would have a tendency to chop up the straw and consume unnecessary power. It also makes separation more difficult to have the straw cut up, as it packs together more than if the stalks are left comparatively whole.

The teeth sometimes hecome loose and cause delay. This is more true of new teeth when being first used. This is on account of their not fitting perfectly and the terrible strain they are subjected to when the straw is compressed in passing through, causes them to move in the bar slightly and each time they move the nut loosens a little and they are soon loose enough to strike and rattle. When new teeth are put in they should be watched carefully and tightened up occasionally until well seated when they will stay without further attention. But the practice of some threshers is to give the teeth no attention until they begin to rattle and make a noise. Much time will be saved by going over the entire cylinder, having new teeth, with the wrench once or twice a day and see that every nut is set up tight. Many devices have been tried to keep the nuts from working loose, some of which have points of merit. Some use wooden bars inside of the cylinder bars; the spring or natural tension of the wood serving to permit the tooth to spring a little and still remain tight. A twisted or spiral steel bar on the inside has been used to take up the wear. Teeth do not seem to loosen as badly in double bar as single bar cylinder on account of the extra length of the shank to hold them from side movement of the tooth when the straw passes in in excessive quantities. Fig. 2 illustrates one method, which is in use, by which to hold the nuts from 
turning by using a spring steel washer under the nut. Both square and round shanks are in use. Teeth should be made of steel, sufficiently hard to prevent too rapid wear. Worn cylinder teeth retard the straw from entering the cylinder freely and should be replaced with new ones as soon as they become very much worn.

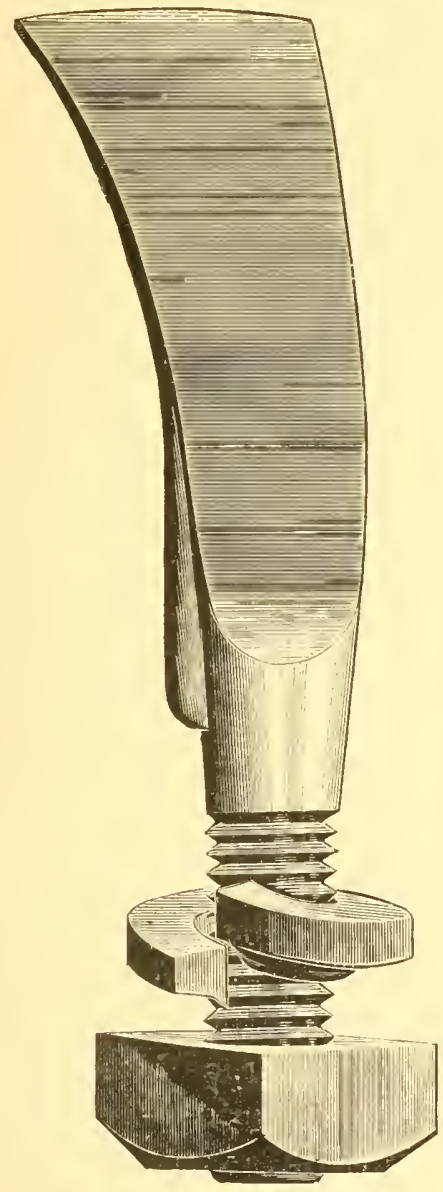

CYLINDER TOOTH WITH LOCK WASHER.

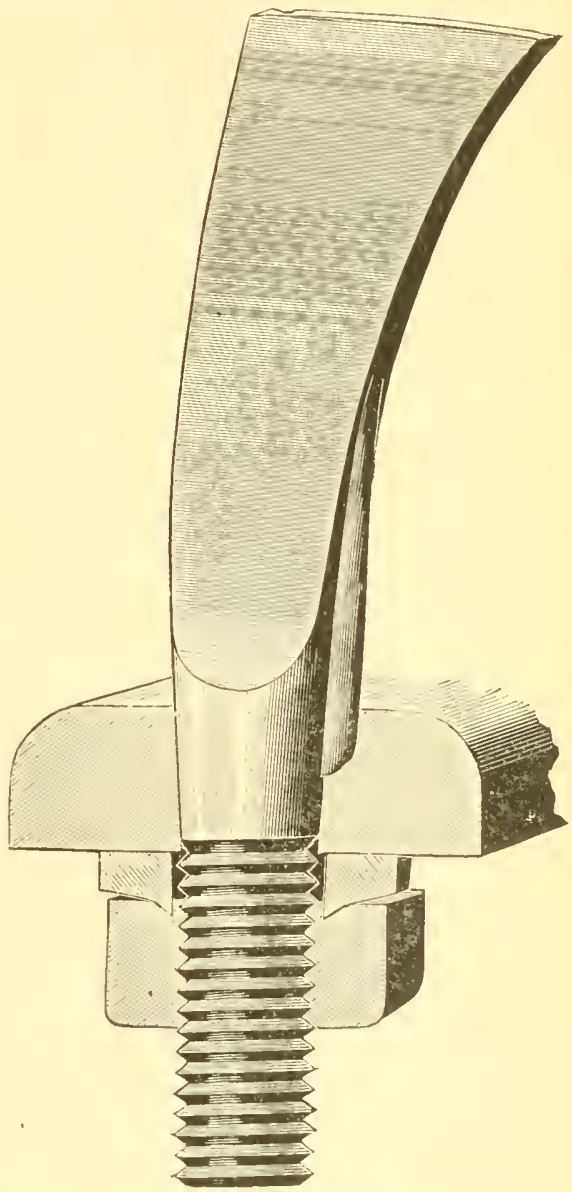

TOOTH IN CYLINDER BAR, WITH LOCK WASHER IN POSITION AND NUT SCREWED UP.

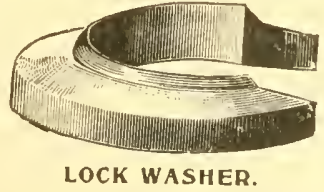

Fig. 2. 


\section{BEATER.}

The office of the beater is to take the straw from the cylinder as fast as threshed and pass it back to the separating device. There have been many arrangements planned and used for this purpose. The form in common use at the present time is a fan-like drum set in a position for the straw and grain to strike against it as it comes from the cylinder and pass either under or over it. It also serves as a check to the flying kernels from the cylinder which would otherwise be thrown back into the straw and thus retard separation.

There are also other devices in use for passing the straw back from the cylinder, one of them is shown in Fig. 3. It consists of a set of forks placed to work over a slatted rack located back of the cylinder. Still another form is a drum filled with spikes something like a cylinder, as shown in Fig. 13, while some machines work very well without a beater at all, letting the cylinder deliver direct to the separating device. The chief object of the beater seems to be to keep the straw from filling up near the cylinder to such an extent as to cause it to wind and carry back around the cylinder. As a separating device it does not seem to be of much benefit as its rapid motion has a tendency to carry the grain along with it and throw a portion on top of the straw as it passes back. The beater should be run only fast enough to prevent it from winding in damp or soft straw, as it increases its tendency to throw the grain. Some difficulty has been experienced in having the beaters wind in long or damp straw. The cause usually having been too slow a speed, or the position in which it is set.

The Checkboard is a sheet-iron apron hung just back of the beater, to arrest flying kernels. It is an important factor and is sometimes placed too near the beater to permit it to work freely. It should be sufficiently long and adjusted to come down low enough to arrest all flying kernels that come from the beater and cylinder as they would be thrown back on top of the straw so far towards the rear of the machine as to be lost with the straw. The weight of this check-board some times effects the action of the straw as it passes under it serving as a compressor. As the straw leaves the beater it is very loose and fluffy and in passing under the check-board is reduced by its weight and action. This will be referred to again under the head of Operation and in the working of the various types of machines. 


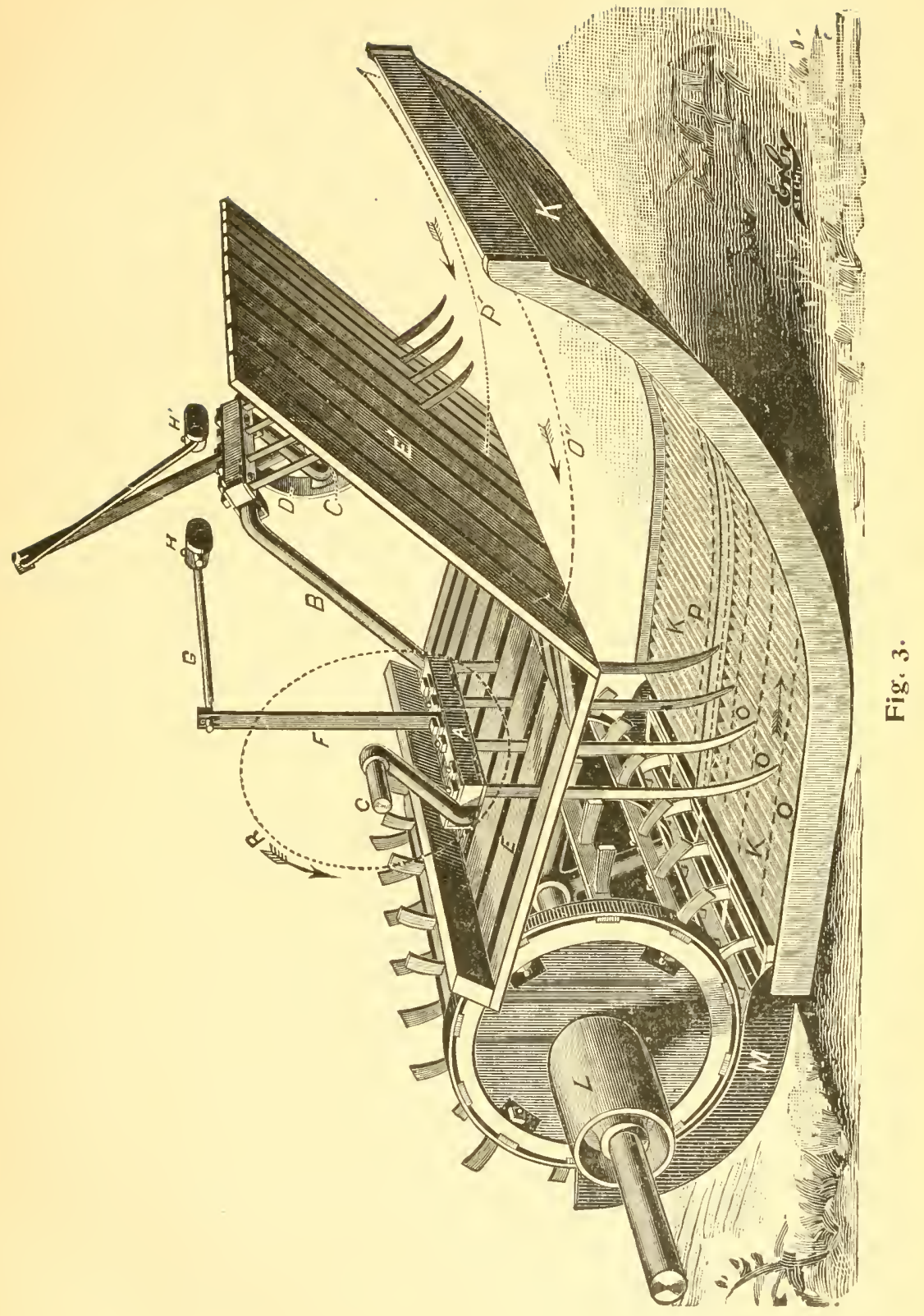




\section{Separating Devices.}

One of the most important features of a thresher is the Separating device. Upon this depends the saving of the grain. After the cylinder has shelled it from the straw, it is left for the separating device to pass the straw to the stack and direct the grain to the shoe or fanning mill to be cleaned.

The cuts on the following pages serve to illustrate the various types and combinations of devices in use at the present time. While there are many combinations and different arrangements in use they may be divided into two or three general classes. First, the vibrating or oscillating rack or table, and second, the traveling raddle or straw rake, or the combination of these two. There are also accessories used in connection with these, such as revolving pickers or rakes, beaters and fingers that will be considered in their turn. Each one having merits of its own, it would be hard to say which device is the best as each machine has combinations peculiar to itself.

It is not intended that this book shall show any preference but will try to faithfully explain the working and functions of each, leaving the reader to judge which is best adapted to his particular use. When the principles and laws upon which a device works are understood it will be easy to discern its merits and demerits.

While the separator seems to be a very simple machine, there are some parts and principles that are so puzzling that no one yet has devised one that will save every kernel in all kinds and conditions of threshing, and until that time comes there is room for improvement.

The inclination at the present time is toward faster threshing, having a tendency to overtax the capacity of the separating devices, as they all depend on gravity to cause the kernels to fall from the straw. Even though this takes but little time it is enough to cause a limit to the amount of grain and straw that can be handled with any of the various devices now in use; for, while we wait for gravity to do its work the straw is increasing in bulk and quantity. If the straw is passed too rapidily through the machine it has a tendency to carry a portion of the grain along with it, while if we reduce the speed of the traveling column of straw it is plain the said column will be correspondingly increased in size and quantity, which of itself is a serious difficulty to contend with 
in separation. It would be well for the intelligent thresher to bear this in mind and not crowd his machine beyond its natural capacity as the result will surely be unsatisfactory. However, any of the separating devices now in use will handle enormousiy large quantities of grain and straw when used and operated with intelligence. The various types of separating racks or tables are usually constructed of slats leaving spaces through which the grain may fall and the straw be carried along its upper surface.

The straw is caused to pass along by means of the motion imparted to the rack by the use of a crank. Insome, this motion is concave, in others convex, while in others the rack partakes of the rotary motion of the crank and makes a complete revolution.

The object of the motion is to thoroughly agitate or stir the straw in such a way as to permit the kernels to fall out, and at the same time move the column of straw along toward the rear of the machine.

We may imagine a quantity of straw intermingled with kernels of grain held in position by being lodged between the stalks and leaves. Now it is plain that we may take this bunch of straw and grain and handle it as a whole, and if we toss it up and down or do whatever we may and not move the stalks as related to each other, the kernels will still remain lodged in their respective places. Iut in order to have them fall out we must move the stalks about among themselves to dislodge each kernel from its resting place, and the milder and more perfectly we can do this the better the result.

The ordinary vibrating rack acting on the under side of a quantity of straw has a tendency to jar and compress it at each upward stroke of the rack. The straw of its own elasticity will expand again to its normal condition while up in the air free from the rack. Thus the straw receives a succession of jars or strokes on its under side, which will be more effective when the straw in falling comes in contact with the rack on its rising motion at one-half of its stroke. It then will receive the most sudden and severe shock on account of the rack traveling the fastest at this particular point of its stroke. When the rack first starts on its upward motion it travels but slowly, but continues to increase its speed until one-half of the full height is reached. The motion then continually decreases to the upper end of the stroke; the same is true of the descending motion. This is owing to the peculiarities of the crank motion by which it is operated. 
Now it is plain that if the quantity of straw and grain should lie on its upper surface and vibrate up and down with the rack, not moving any higher, the stalks would remain in their respective positions and not give the kernels a chance to fall out. But to be effective each stalk must be moved as related to its neighbor in order to accomplish the desired result. And when you have mastered this principle and got it thoroughly fixed in your mind the problem of separation will be the more easily understood.

The motion of the rack should be such that its upward stroke will cause the straw to continue its course slightly and permit the rack to descend from beneath it. Gravity then will begin to act upon the straw and cause it to start on its downward motion; the straw at first moves but very slowly but increases its speed as it descends toward the rack, the momentum thus attained will cause it to strike the ascending rack with a sharp and jarring motion at the midway point before mentioned, if it has been properly timed. The weight of the straw will cause it to be pressed against the rack with force, while the stiffness of each straw that comes in contact with the rack will have a tendency to move it as related to its neighbor, and as soon as released at the upward end of the stroke will again expand to its normal condition.

This jarring, compressing and expanding movement accomplishes the desired result in a remarkably perfect manner, when the vibrating column of straw is not too thick and bulky. If the column of straw is so deep that the jarring motion of the rack is not felt through its entire column the results are not as good. The upper part of the column of straw will float along without receiving the essential jarring motion of the rack on account of the springiness or elasticity of the intervening straws. While on the other hand if the rack is made to vibrate faster to throw the straw higher, the tendency is to also throw the grain; be. ing of the greater specific gravity it will continue its upward course in excess of the straw if the opportunity presents itself and thus retard separation.

The ordinary raddle is constructed of belting running over pulleys with laterally secured slats that will permit the grain to fall through and carry the straw along on their upper side. They seem to accomplish their work in a more perfect manner when their motion is quite rapid, as this keeps the sheet of traveling straw much thinner thus giving the kernels a better opportunity to fall out. The raddle should be 
of sufficient length to give the kernels ample tlme to fall clear through the slats before reaching the end.

Some raddles are agitated while in motion by means of traveling over an irregularly shaped pulley which produces a rapid jarring motion, having a tendency to move the stalks of straw slightly among themselves.

The point of contact as the straw falls on to the raddle needs special attention. The straw at this point should be quite thin and loose for if large or hard bunches are permitted to fall on it, the tendency is to carry them along in one mass, not giving the kernels a chance to fall out. As the straw falls the slats of the raddle in their rapid motion catch the straws in contact and give them a sudden start or jerk that has a tendency to loosen or move the straws from each other. The greater portion of the separation is done at this point, and it seems to be more effective if the straw can fall a little distance so as to be traveling at right angles to the line of motion of the raddle when they come in contact. It also causes the straw to strike the slats with more force, giving it a better hold to pull it apart. Whereas if the straw is traveling in the same direction as the raddle when it comes in contact, it does not receive the same jarring and pulling apart motion, but passes along with ease, without change of direction or position of the stalks as related to each other, making it impossible for the enveloped kernel to fall out.

In the combination of the vibrating rack with the raddle, the straw usually passes over the rack first and delivers on to the raddle. At the point of delivery, the straw is pulled apart and thinned by the action of the raddle, its rapid motion having a tendency to take the straw much faster than it is delivered to it. This pulling apart process greatly assists separation at this point. There are also other combinations that will be noticed in connection with the illustrations of same.

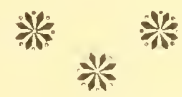




\section{The Shoe.}

The shoe, or cleaning mill, is an important part of the separator and upon it depends largely the good work of the machine. In separating the grain from the straw there is a large amount of chaff and refuse delivered to the sieves with the grain. This is cleaned from the grain by passing it over a series of sieves through which a blast is being forced. A great deal depends on the perfect working of the shoe, whose office is to thoroughly clean the grain without waste, and in quantities as fast as delivered to it.

There are three things to be considered in a shoe, and on the arrangement of these three depends its working, viz, the sieves, the blast and the motion. The sieves should be adapted to the kind of grain being threshed and as few used as are necessary to do the work, as more retard the blast and catch straws and sticks. The blast should be sufficiently strong to insure its continued flow through the sieves, even when they are heavily loaded. The motion should be sufficiently strong to insure the chaff and kernels being moved on the surface of the sieve.

The fans for producing the blast are usually constructed of a centrally revolving shaft with radiating arms, on which are secured fans to cause the air to rotate with it and produce the blast by admitting it at the ends, and forcing it out by centrifugal force at the periphery.

Some are revolved in one direction and some in the other. Those where the top of the fan travels toward the sieves are called overblast fans, and when constructed to revolve in the opposite direction, they are called underblast fans. Both styles are in common use and accomplish the work intended. There is a large variety of sieves made and used. Of late years the inclination seems to be favorable to the perforated metal and corrugated iron ones, though wooden and wire ones are in use. The proper qualifications of a sieve are to permit the grain to fall through, pass the chaff and sticks over it, direct the proper amount of blast in the right direction and prevent the straws and sticks being retained in the meshes. The usual practice is to use a sieve adapted to each class of work, though there are some combinations that operate well on different kinds of grain. The usual plan is to have the upper sieve, called the chaffer, secured permanently and of sufficiently large 
meshes to adapt it to the coarsest kinds of grain while the lower ones are made interchangeable, to be varied according to the kind of work being done.

The openings in the sieve should be of sufficient size to permit the clean kernel to pass freely, and only enough of said openings to allow a proper quantity of blast of air to pass through. If the openings are too small or not enough in number to prevent the grain to pass through freely as fast as it falls onto the sieve, the result will be to cause it to overflow into the tailings spout and be returned to the cylinder a useless operation which greatly reduces the capacity of the machine by increasing the quantity of grain to be handled. If the openings are too large the tendency is to permit heavy sticks to pass through with the grain. These openings should be of such a nature as to cause the blast of air to flow in the proper direction which is found to be at quite a perpendicular angle. This will prevent the blast from having a tendency to blow the grain along the upper surface of the sieve. If there are too many openings, as in a wire sieve, the tendency is to permit too much air to pass through, and cause too much of a blast above the sieve to permit kernels that are lifted from the surface to again fall before reaching the rear end.

The blast is an important feature of a well regulated shoe. It should be of sufficient quantity to lift all light matter and of sufficient force or pressure to cause a continuous and uniform flow through the meshes of the sieve. It is essential that this blast should be the strongest directly in the opening or meshes of the sieve, while a short distance above the surface it should be mild and light When these conditions are secured should the blast lift a kernel it will ascend but a short distance before it will again return to the sieve, while if the blast were as strong above as in the meshes, the kernel would be blown out with the chaff, and wasted. This condition is accomplished by making the blind portion of the sieve in proper proportion to the opening of the meshes; this in practice is found to be about as five is to seven. That is to say, for the solid portion of the sieve to be about 5-12 of the surface while the opening in the meshes constitutes the other 7-12. By reflection it will be observed that a short distance above the sieve the blast will be only 7-12 as strong as directly in the meshes of the sieve. It is also well to observe that this statement is more nearly correct when the blast is traveling in an upward direction nearly at right angles to the surface of the sieve. 
The blast should be sufficiently strong to insure its continual flow under all circumstances and conditions, but not of enough speed to blow any of the grain over with the chaff. There is a difference between a blast of strong pressure and a blast of fast speed. A blast of air may be traveling comparatively slow and still go with force and be difficult to stop, like that produced from a slow moving air pump; or it may be moving quite rapidly, but with no particular force more than the inertia produced by its own weight, like the breeze of a summer day or the stroke of a lady's fan The least obstruction would stop or turn such a blast. The kernels of grain will fall through a blast of any pressure or strength, but will not fall through a very fast traveling blast.

The chaff is easily lifted on account of its light specific gravity. To do good work then, it requires a mild or slow blast delivered with strength or force. This blast should be spread under the entire surface of the sieve and be made to flow through every mesh. It should be the strongest and of greatest quantity at the front end of the sieve where it receives the grain and chaff, for it is here where the greatest work is to be done in lifting the sheet of chaff intermingled with grain, and decrease in quantity and pressure toward the rear end where less work is required. Then if a light kernel has been lifted with the chaff at the front end, it will give it a chance to fall before reaching the rear end of the sieve.

If the blast is made to pass through the chaff as soon as it enters the upper sieve, it will lift it and cause it to separate and expand, the lightest flying out first giving, the kernels a free opportunity to fall through the sieve much more quickly than if the blast were not strong enough to keep the meshes open and cleared of chaff. Besides, if the blast ceases to How through any of the meshes, the fine dust and chaff will fall through and cause the second sieve to be overloaded, and thus the grain may retain a part of the chaff and dirt. The motion of the shoe should be sufficiently strong and rapid to move the grain and chaff on the surface of the sieves. Too strong a motion will interfere with the kernels in falling through the meshes properly and cause the grain to be carried over, either with the chaff or into the tailings spout. It is found in practice that the upper sieve or chaffer requires a longer and more positive stroke than the lower sieves. This is on account of the excessive quantities of chaff and cut up straw to be 
carried along. For this reason the upper sieve or chaffer is usually placed in a different frame and given a longer stroke while those in the shoe receive a shorter and more rapid stroke.

The coarser and looser the material to be handled the longer and more vigorous the motion should be. The straw rack loaded with loose fluffy straw requires quite a long stroke to be effective. The conveyor and chaffer sieves will use less, and the shoe sieves still less.

It will be seen, that if the straw rack had no more motion than the shoe it would not handle or scarcely move the straw at all. While if the shoe had as much motion as the straw rack, it would throw the grain in such a fierce manner as to prevent much of it from passing through the sieve. This is on account of the difference in elasticity or springiness of the materials to be moved. It is then quite essential that the motion should be adapted to the class of work to be done. In end shake sieves, i. e., the stroke being endwise of the machine, this motion should be upwards and backwards with more of an uplift, and should be only sufficiently strong or rapid enough to cause the grain to be carried along in as quiet a manner as possible.

The sieves should be stiff and rigid enough to not permit them to spring much in the center, for if they do it will make the motion 100 strong there, causing the grain in the center of the sieves to be thrown too high, preventing it from properly falling through the meshes. This will be apparent when we consider the frame of the sieve traveling two inches at each stroke and making 250 strokes per minute, the sieve then will travel 500 inches per minute. Now if the sieve springs one inch each stroke, the center of the sieve has traveled three inches each stroke or 750 inches each minute which may be a motion entirely too strong, and it will be seen that the center of the sieve receiving the stronger motion will act upon the grain in a more vigorous manner than the portion of it which has less motion.

It is also necessary for a shoe having a weak blast to have a stronger motion to assist in carrying off the refuse and chaff at times when the blast is overtaxed, such as in wet or damp threshing or when an undue amount of chaff and cut straw loaded with dust is delivered to it.

In side shake shoes, i. e., when the motion is sideways to the machine, the motion should be sufficiently strong and long to cause the 
sieve to move under the grain and chaff, and keep it in motion to aid the blast in carrying it along toward the rear end.

The blast may be at a greater angle from the perpendicular in side shake shoes, as it is the only means of carrying the chaff and refuse along to the rear end. While in the end shake, the upward and backward motion will assist in moving it.

The motion in a side shake may be given an upward rocking at each side as the stroke is finished. This is accomplished by using comparatively short hangers and adjusting the hangers so they will be at an angle (sideways to the machine.) As the shoe is moved sideways one side of it will continue to rise, and the other to lower somewhat, causing it to give the grain a slight upward motion at each stroke. This motion varies in different places on the surface of the sieve, being nearer parallel in the center. 


\section{Figure 4}

No. I, Cylinder.

No. 2, Grate made of tlat strap iron.

No. 3, Beater.

Nos. 4-4-4-4, notched fish backs in the straw rack, connected by open slatwork in the bottom

Nos. 5-5-5-5 are the open slat work running across the separator on the lower edge of the fish backs.

No. 6, Grain Conveyor.

No. 7 , Lipped Chaffer.

No. S, Set of Wire Fingers.

No. 9, Upper Sieve.

No. Io, Lower Sieve.

No. II, Fan Drum.

No. 12, Fan.

No. I 3, Upper Wind Board.

No. I4, Lower Wind Board.

No. I 5, Grain Auger.

No. I7, Tailings Elevator.

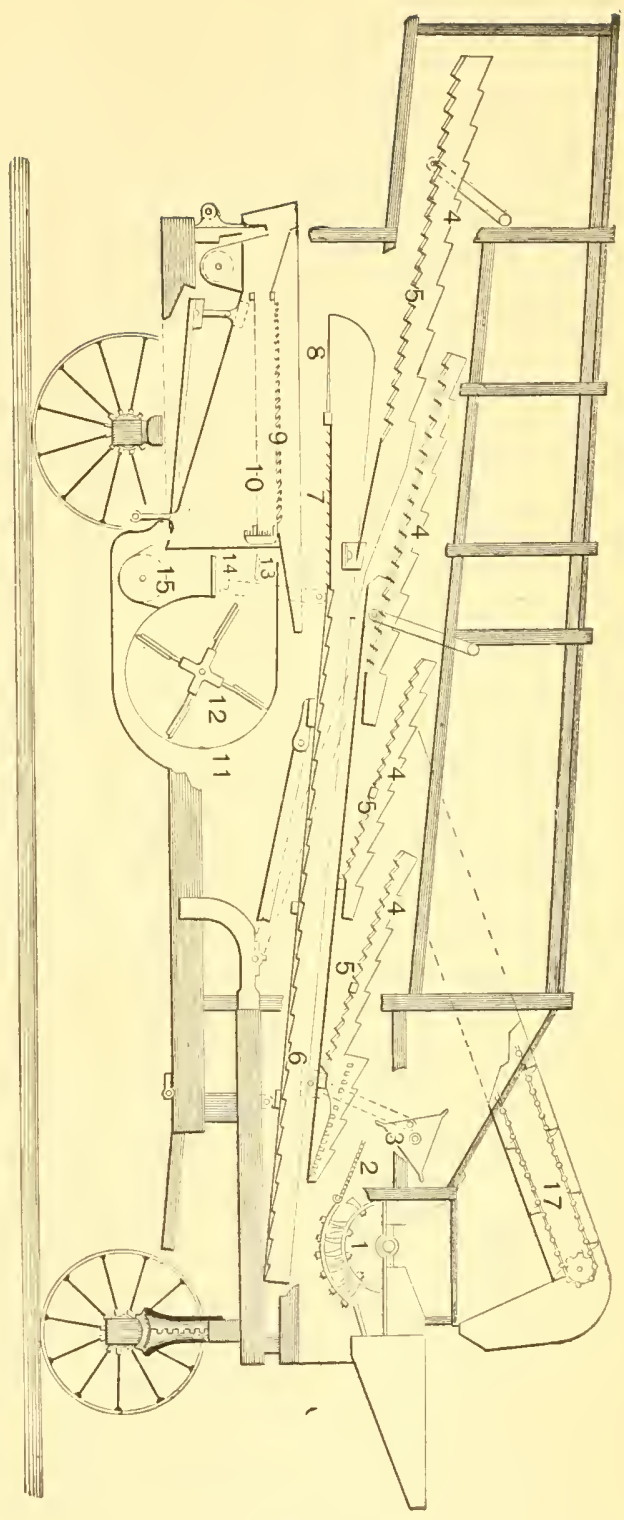

Fig 4. 
Fig. 4, shows one kind of Separator with vibrating straw rack; threewinged beater; end-shake shoe, and overblast fan. This type of beater being comparatively small and composed of three wings, takes a firm hold on the straw as soon as it passes from the cylinder, and may be run quite fast with advantage.

The check-board or apron (not shown in cut) should be far enough back from the beater to leave enough of a reservoir to give it a clearance in hard feeding or slugging.

The straw rack is suspended on links or hangers which gives it a concave motion. It will be observed that this motion is different from a convex motion where the rack is supported on rockers, or where it is held by the upper end of the link instead of the lower end. It might be represented in this case by the inside of a rim of a wheel, while in the other case by the outside surface of the rim. If the wheel were set in motion in the first case, an object on the inside of the rim would be held against it by centrifugal force, while in the other case an object on the outside would be thrown off by centrifugal force.

The straw rack moves only a short distance, but as far as it goes any given point travels in a circle, the same as the rim of the wheel, using the hanger as a radius to make the segment of the stroke. During the upward stroke of the rack this has a tendency to cause the straw to bear down and hug to the rack much closer than if the motion were convex.

The shorter the hangers are, the more sharp will this curve be, and the more closely will the straw cling to the rack in its upward stroke. The position of the hanger determines the direction of this stroke or motion, which always is at right angles to the hanger. If the hangers were perpendicular, the motion of the rack would be horizontal, and would not carry the straw in either direction. But by inclining the top of the hanger forward, the rack partakes of an upward motion, just in proportion to the angle of the hanger.

A rack that has the concave motion begins the upward stroke with a motion toward the horizontal and finishes more toward the perpendicular. While a rack with a convex motion begins with more of a perpendicular and finishes toward a horizontal motion. For this reason the hangers should be adjusted nearer to the perpendicular in the concave than in the convex motion. 
The rack withia motion toward the horizontal should have a longer and more rapid motion than that imparted to one of nearer perpendicular motion, for the reason before mentioned, that the straw hugs closer to the rack on the upward stroke, and requires a sharper throw to cause it to ascend and leave the rack at the upper point of the stroke. But a point is gained by the expansiveness of the straw as it leaves the rack permitting the kernels to fall out.

The first part of the stroke being towards the horizontal, has a rasping motion, using the weight of the straw as a resistance, which tends to move the straws among themselves dislodging any imprisoned kernels.

The straw in passing over the upper point of each riser is pulled apart as it falls to the next riser. This is especially true when the column of straw is not too thick and heavy to be thoroughly bent and pulled apart. In hard feeding the greater part of the separation is done at this point.

The chaffer sieve is fastened to the frame of the conveyor and receives the same stroke. This insures the continuous travel of the chaff without the aid of the blast to carry it along.

The air in passing from the fan strikes the blastboards (13 and 14) on their upper surface and can be directed to any part of the sieves by changing the angle of the blastboards which are adjustable. 


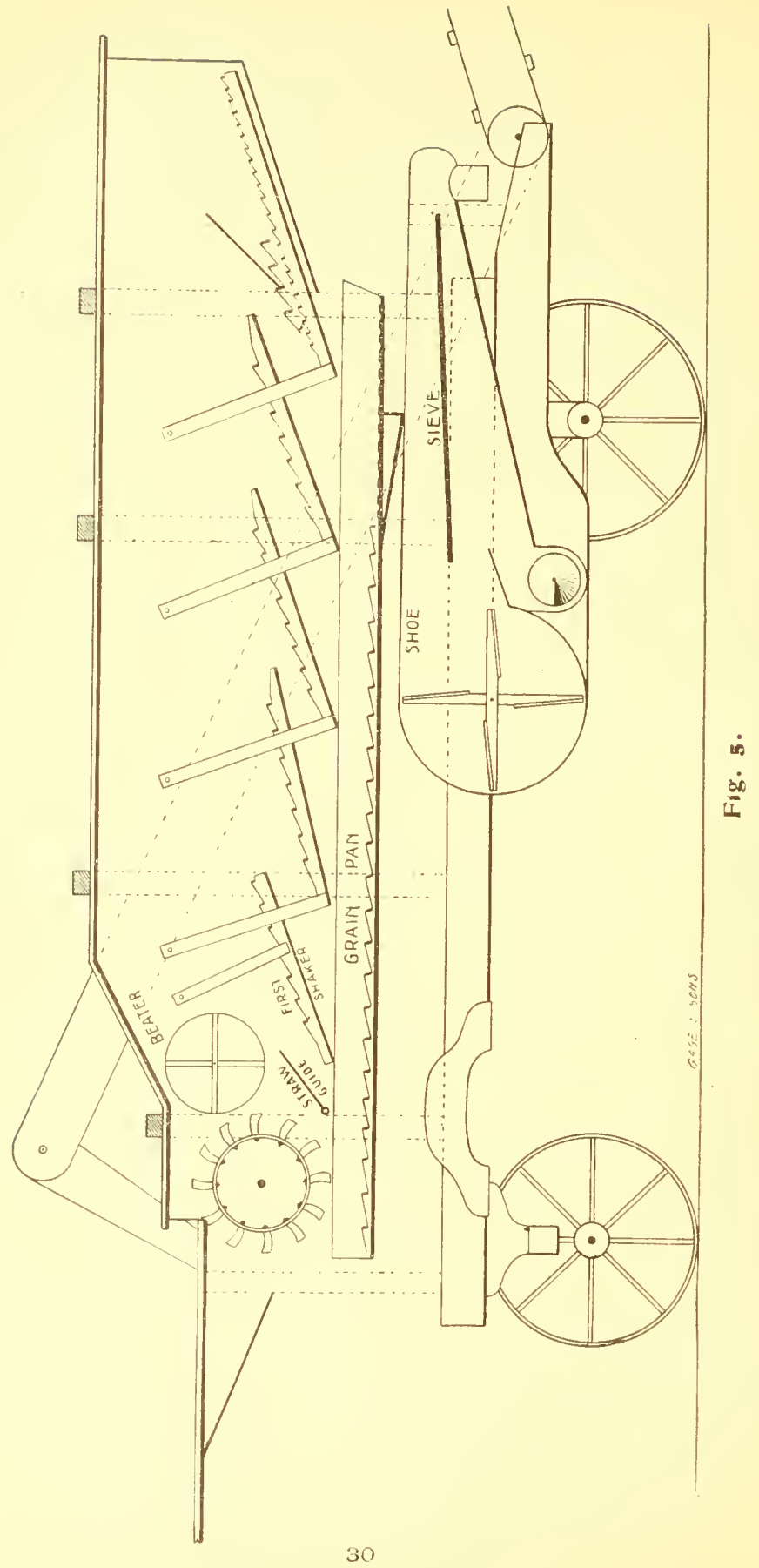




\section{Figure 5 .}

Fig. 5 represents the ordinary 1 2-bar cylinder, grate or straw guide of round fingers, and subdivided straw rack, vibrating grain conveyor and overblast fan.

The straw guide between the cylinder and beater is hinged, and is adjustable to direct the straw higher or lower.

In this plan of straw rack each section has a concave motion and works independently of the other.

The hangers are rigidly secured to each section of the rack, motion being imparted to them by means of a connecting rod. In vibrating, each rack uses the upper end of its hanger as a center to travel to. This causes the rear and upper end to have a longer and more perpendicular motion than the front or lower end, and has a tendency to break and pull apart the column of straw as it passes over the highest points.

The motion should be strong and rapid enough to insure the straw from becoming too deep and thick in fast threshing. These motions are in unison, all the racks working simultaneously, or varied and irregu. lar, regulated by the way the hangers and connecting rods are disposed.

As the grain falls through the slat work of the rack, it is received on the grain pan by which means it is conveyed to the sieves, where it is acted upon by the blast.

As the blast leaves the fan it strikes the stationary blast board over the grain auger and is deflected up and back toward the sieves at an angle along their entire length. 


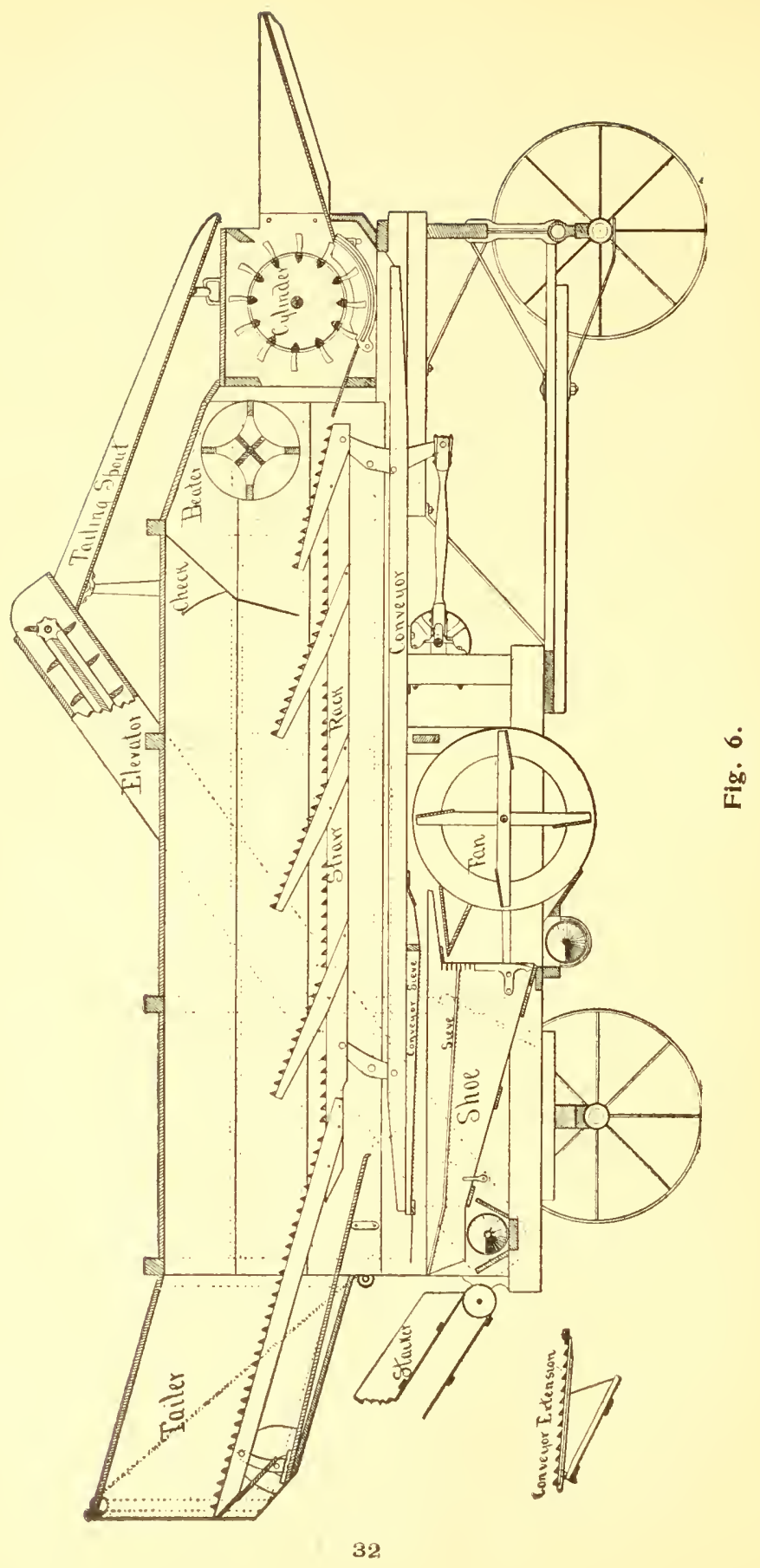




\section{Figure 6.}

Fig. 6 clearly represents a 1 2-bar cylinder, 4-wing beater, straw rack of one piece, underblast fan and end shake shoe.

The straw passes under the beater on to the straw rack which has a convex motion.

The check board arrests all flying kernels coming from the cylinder and beater.

This straw rack is of one piece throughont its entire length. It has a series of risers over which the straw is made to pass. As the column of straw passes over the point of each step it is bent downwardly, tending to pull apart the stalks of the upper side. Then as it passes between the risers it is curved upwardly tending to elongate the lower side of the column of straw.

This movement of bending the column of straw alternately up and down is calculated to move the straws among themselves and permit the kernels to fall through the rack and be caught by the vibrating grain conveyor below. This is hinged to the opposite end of the rocker arm on which the straw rack is held, thus the two tend to balance each other while in motion.

The chaffer or conveyor sieve is fastened to the vibrating grain conveyor and receives the same motion. A disconnected view of an extension for the conveyor sieve is shown at the lower left hand corner. This may be attached to the rear end of the conveyor sieve and takes the place of the wire fingers shown in cut. The return bottom delivers the grain into the tailings spout.

The blast from the fan strikes the underside of the upper blast board where it is deflected downward to the bottom of the shoe from whence it passes up through the sieves.

The grain and tailings are conveyed across the machine by means of augers.

The tailings are delivered by the elevator to the vibrating spout which conveys them to the feed board in front of the cylinder. 


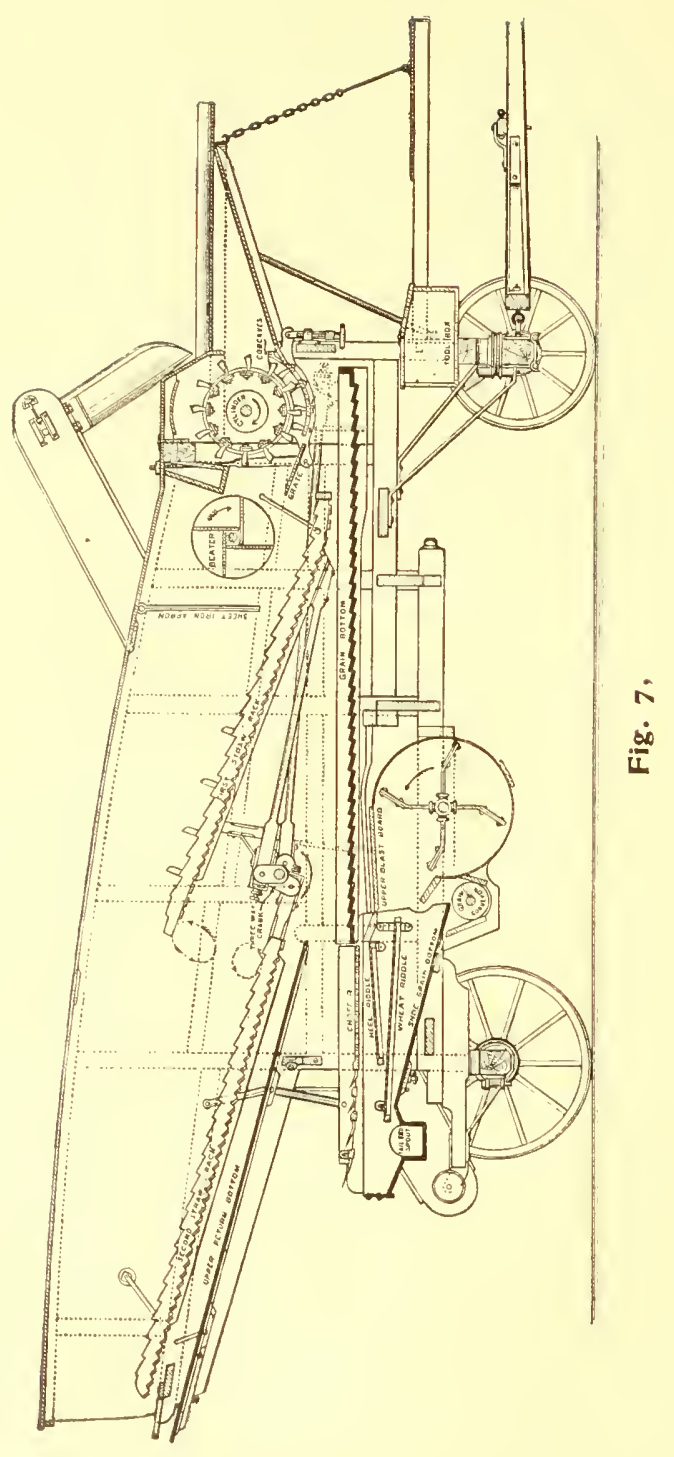




\section{FIGURE 7 .}

Fig. 7 is designed to specially show the movement of the straw rack. At the center it is divided and journaled directly to the crank which is placed midway between the two parts, this gives the two center ends of the rack a circular motion. The other ends front and back are link supported which gives them a concave motion, while the central portion of each rack partaking of the motion of both, causes an elliptical motion, the long part of the ellipse being parallel to the rack.

This style of rack will admit of a very strong and vigorous stroke without throwing the grain, as near the central ends of the rack where the rotary motion is most apparent, the motion is reversed at ihe lower part of the stroke. It will strike the straw on its upward motion going at an angle toward the cylinder. The straw will then adhere to the rack until the upper part of the circle is reached where it will receive a backward and upward throw. The motion thus reversed while the straw is in contact with the rack, has a tendency to move and pull it apart, changing the straw's position as related to each other. This is especially true at the extreme upper point of the first rack.

As the straw falls over on to the second rack it receives a long, vigorous stroke calculated to thoroughly pull it apart at this point giving the kernels an opportunity to fall out.

This mode of moving the rack insures perfect balancing as each rack balances the other by moving in opposite directions.

As the grain is separated and falls through the slat work of the rack it is received on the grain bottom and conveyed to the chaffer and shoe. That coming from the rear rack is returned to the forward end of the chaffer by means of a link supported bottom, thus preventing any straws falling from the straw rack endwise through the meshes of the chaffer and sieve.

This fan is constructed with the wings disposed at an angle to its center, claimed by some to give a stronger blist than those in which the wings stand straight from the center.

As the blast comes from the wing it strikes the blast board above the grain auger and is directed with force against the front portion of the sieves.

The back portion of the chaffer is constructed of fingers to permit any unthreshed heads to fall into the tailings spout to be returned to the cylinder. 


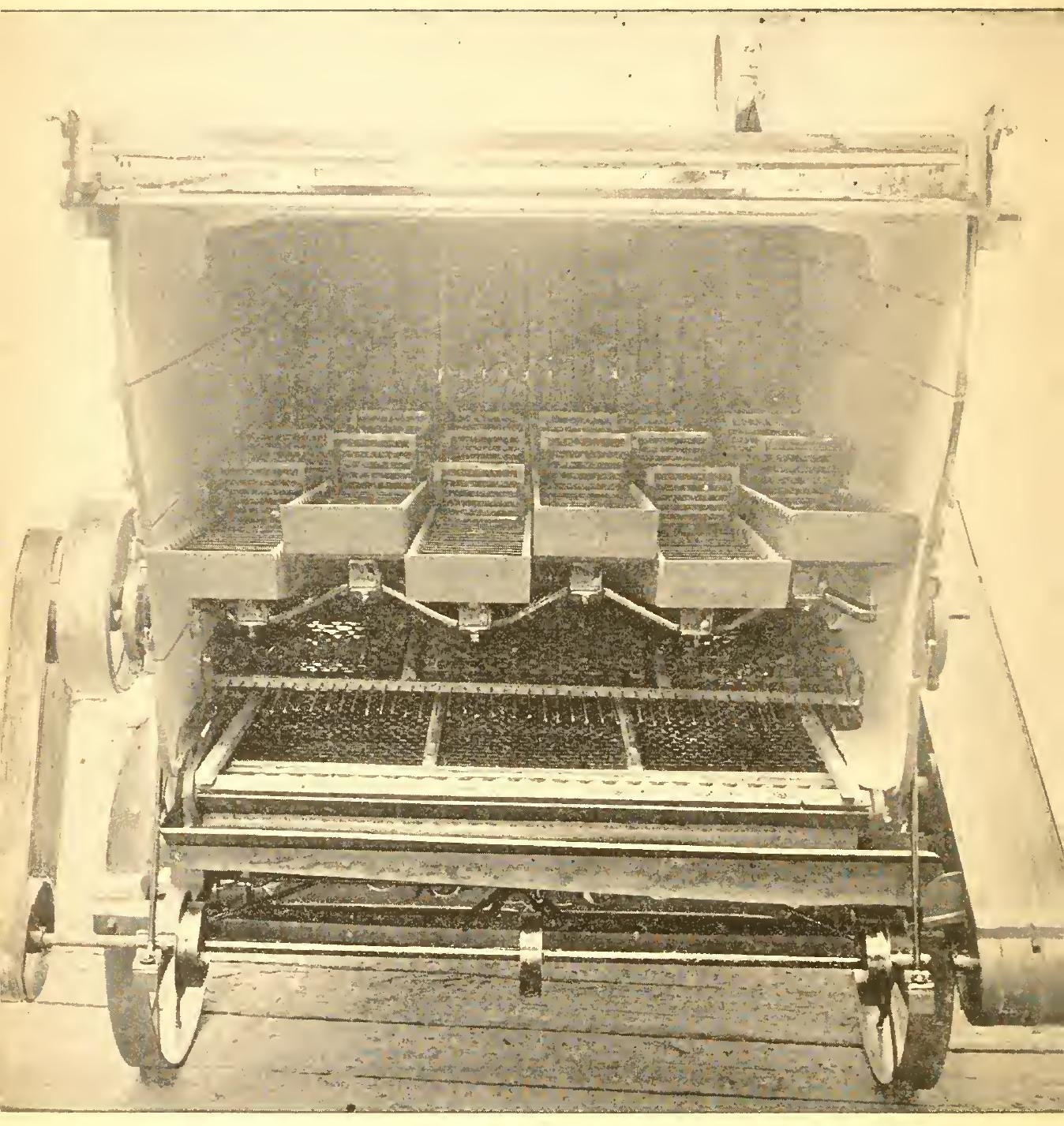

Fig. 8 . 


\section{FIGURE 8.}

In Fig. 8 the straw rack is represented to be divided lengthwise into several sections. The front end running in parallel guides, and journaled to a multicrank shaft at the rear, gives them a straight motion at the front end, and a circular motion at the rear, it making a complete revolution with the crank.

By being divided into sections lengthwise and each section working independently it gives a varied and stirring motion to the straw that increases as the rear is approached.

Each section is also provided with risers which help to further break the straw.

The separation in this plan is accomplished by a stirring, pulling process. As each successive rack moves upward and backward carrying the stalks in contact with it while the rack next to it tends to hold it back; it does not need as vigorous a throwing motion as racks otherwise planned. 


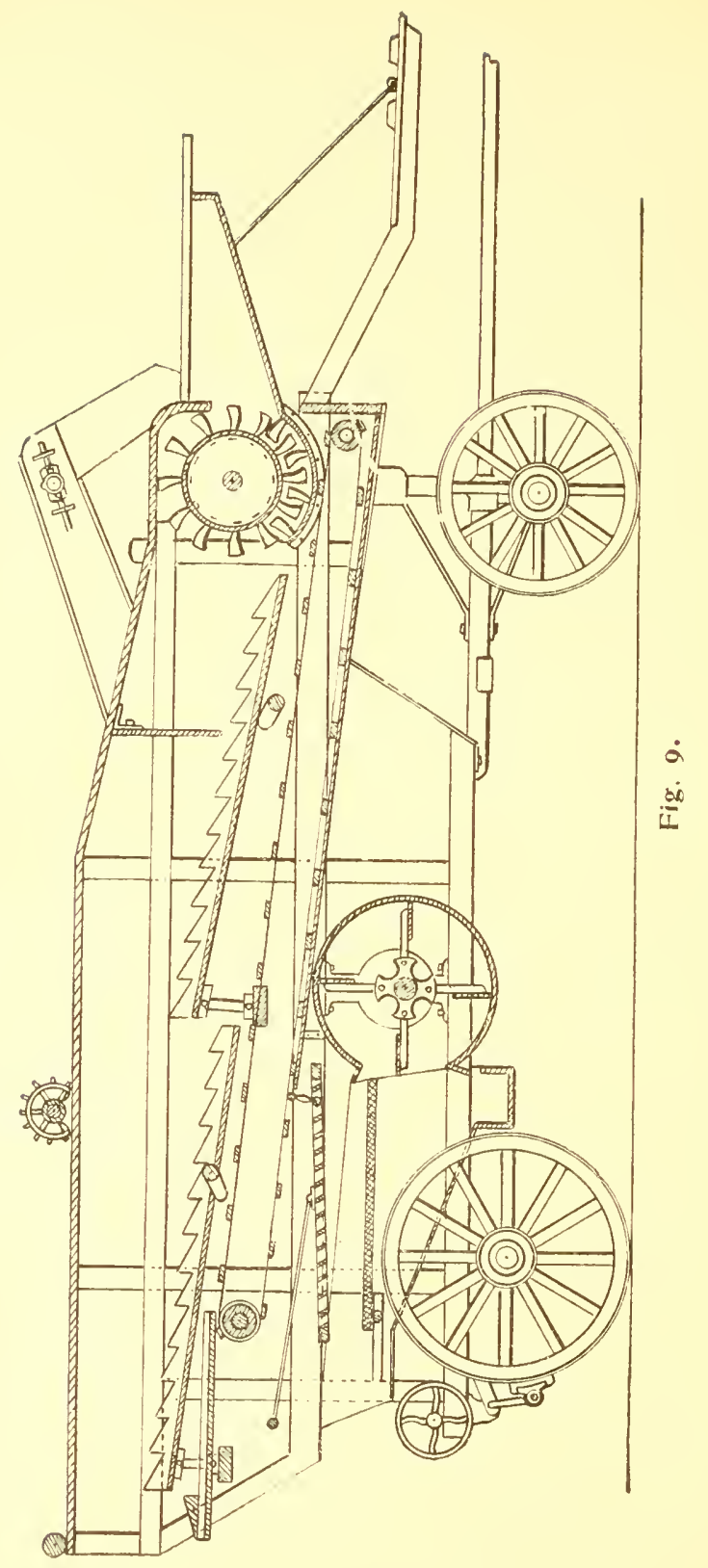




\section{FIGURE 9 .}

Fig. 9 is designed to show the interior of a machine with I2-bar cylinder. Straw racks divided at the center and in sections lengthwise, each section of each end working independently.

The forward ends of each section are given a rotary motion by being fastened directly to a revolving crank placed beneath them, while the rear ends are supported on rocker arms and have a convex motion.

The grain is conveyed back to the sieves by means of a raddle or grain web made of belting with laterally secured slats that catch the grain and drag it along on the tight bottom.

It shows also the chaffer constructed of inclining wooden slats, side shake shoe, and under blast fan placed in close proximity to the sieves.

In operation the beater is dispensed with, the cylinder delivering direct on to the straw racks, a hinged check board being suspended to stop the flying kernels.

As the straw comes from the cylinder, it is a very thin sheet and is deposited on the rack in a very loose open mass. The straw rack having the strongest motion at this point begins pounding it from below as soon as deposited having a tendency to begin separation at once while in the loose form. As it passes back under the check board, it is packed somewhat and reduced in bulk which quickens its speed.

As it goes over the upper point of the first riser it is pulled apart and deposited on the second set of racks to be again operated upon as before.

The racks so operated are self balancing which ought to insure the machine being held quiet while in operation.

As the grain falls through the racks to the tight bottom it is carried back to the cleaning sieves by the grain raddle. Where it first passes on to the upper sieve or chaffer the blast strikes it and removes the chaff.

The incline of the slats of the chaffer are such as to direct the blast well up towards a perpendicular. In this position it will admit of a strong blast without blowing kernels along the surface of the sieve.

The fan being located so near will give the forward portion of the sieves a very strong blast as each wing passes. 


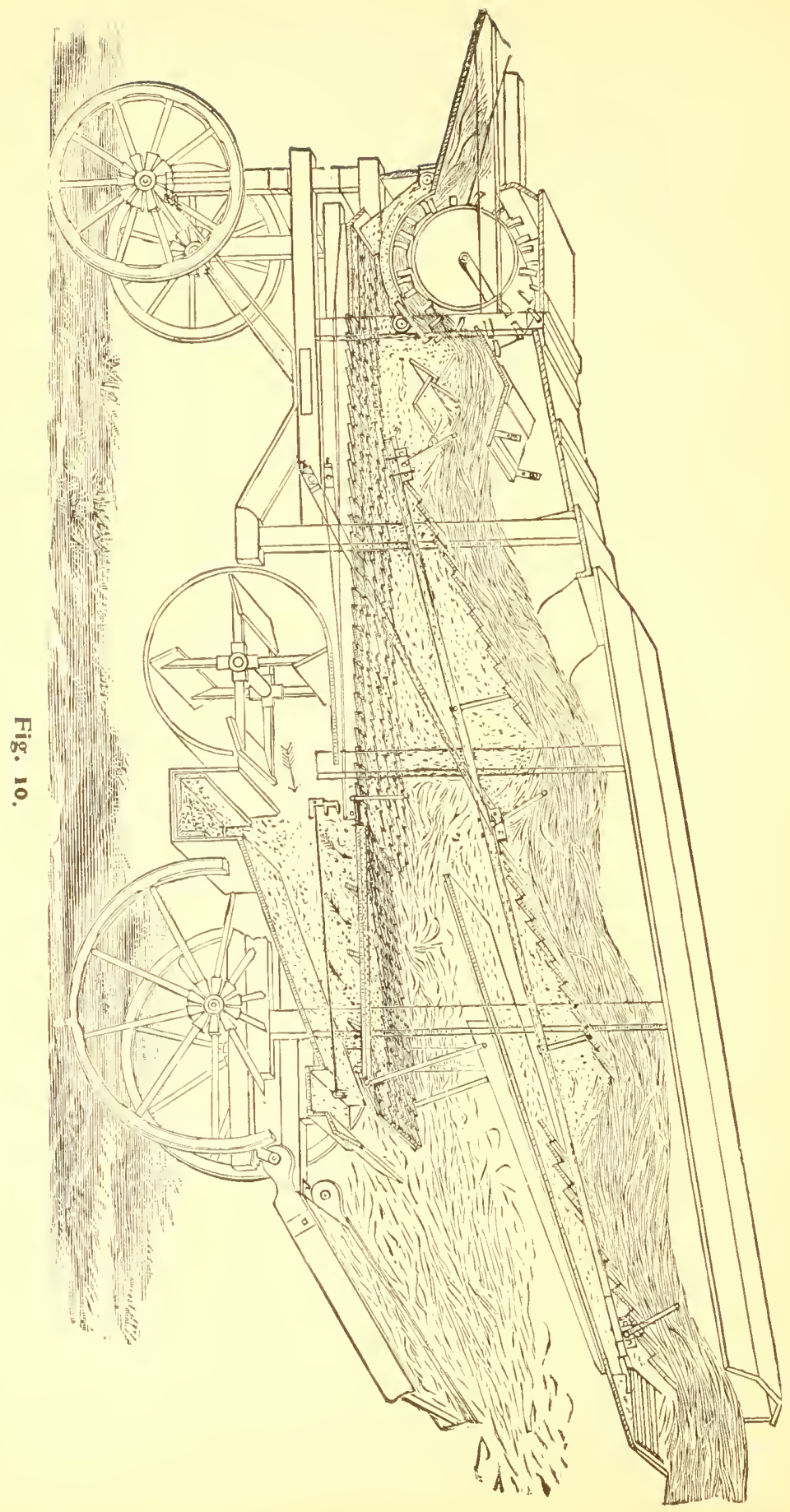




\section{Figure 10.}

Fig. yo represents a machine in operation and shows very clearly the action of the various parts upon the grain and straw.

The cylinder represented is constructed of a cylindrical drum with teeth inserted snd secured by nuts on the inside. Nuts are tightened by inserting a specially constructed wrench to the end of the drum.

The straw passes over the beater which is composed of four wings and revolves in the opposite direction from the cylinder.

The check board above the beater stops the flying kernels.

The straw rack is in one piece and is composed of a series of steps oyer which the straw passes. The rack is made of open slat work through which the grain can fall as it is separated from the straw.

The conveyor located under the rack carries the grain back to the chaffer which is attached to it, and receives the same motion.

The shoe has a side shake with the grain and tailings spout rigidly attached. The motion of the shoe carries the grain and tailings along the inclined bottom

The fan is over blast with the wings set at an angle, and forces a strong blast through the sieves. 


\section{FIGURE"11.}

Fig. I I represents a"machine of the vibrator class with straw racks divided in the center which carry both grain and straw, the straw being held up by notched strips set up edgewise running their entire length.

The rack has also a number of rearwardly inclining fingers hinged to it having an independent vibratory movement imparted to them by means of an adjustable arm on the outside of the frame. As the rack travels backward on its stroke it causes the upper points of the fingers to rise and force themselves into the straw producing a motion well calculated to pull the straw apart. The angle of these fingers can be varied by adjusting the rocking arm.

Motion is imparted to the racks by means of a double crank at the front end connected with each by a pitman so arranged that they balance each other.

Over the rack forward and back of the center are two sets of fingers or pickers having motion imparted to them by means of a crank shaft running across the top of the machine. These are so arranged that while in rapid motion they pick and pull apart the moving column of straw as it passes along the rack, thus assisting separation.

The rear portion of the back rack is perforated to allow the grain to pass down to the shoe.

This shoe is long giving ample sieve room.

The fan is under blast and located a good distance from the sieves thus giving the compressed column of air as it comes from the wings of the fan a chance to equalize and adjust itself before reaching the sieves.

The cut shows the manner of belting and driving the different parts.

The fan and crank shaft is driven direct from the cylinder shaft and the straw pickers from the crank shaft, the straw carrier pulley from the fan shaft, and tailings elevator from one of the picker shafts from the opposite side of the machine.

The tailings elevator extends far enough ahead so the tailings will fall from it and descend by gravity to the cylinder. 


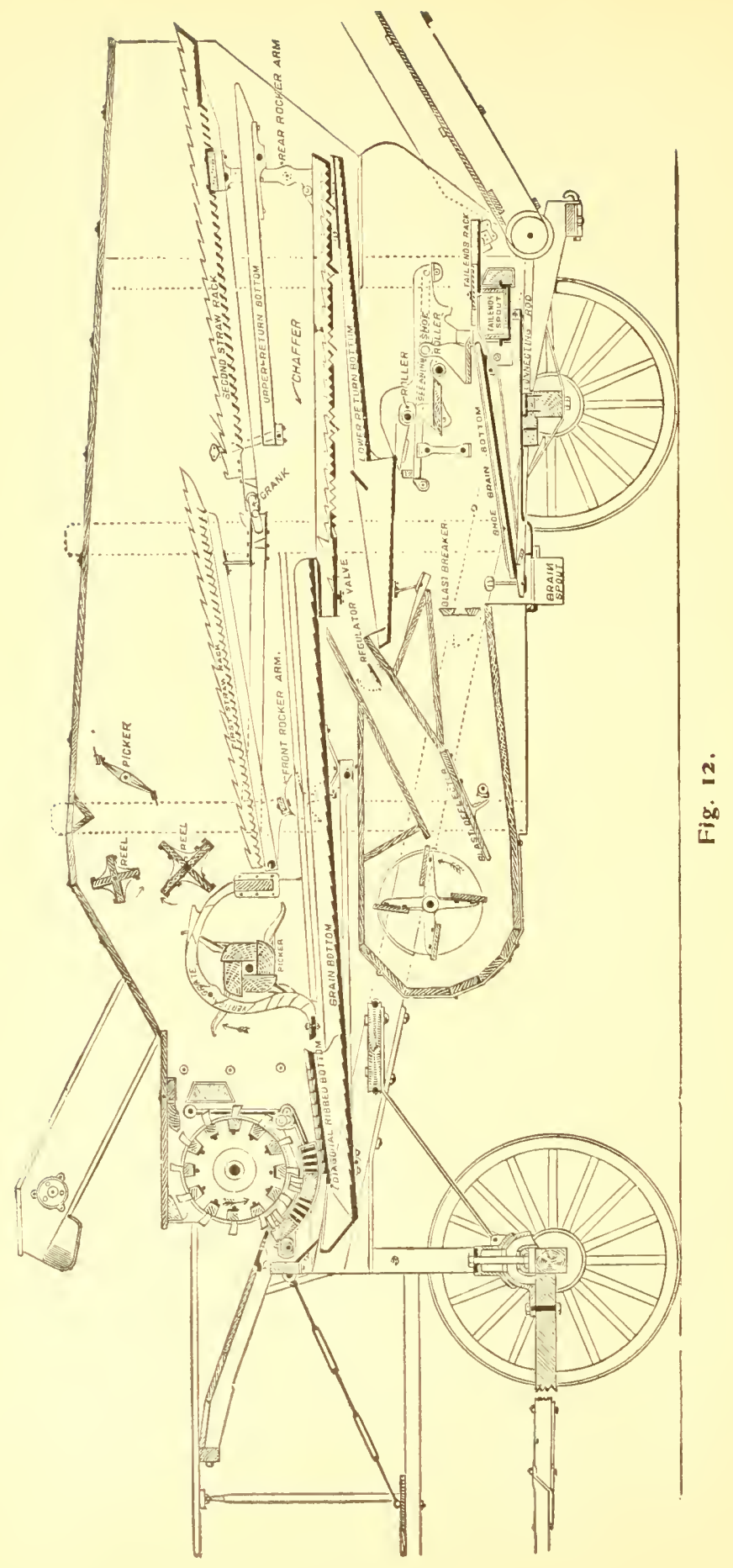




\section{Figure 12.}

Fig. 12 represents a machine with many novel devices peculiar to itself.

Twelve-bar cylinder with wooden bars on the inside through which teeth are secured.

The straw is thrown by the cylinder against a grate in which is placed a revolving picker that passes the straw up and backward to two revolving reels through which the straw passes.

A two winged picker located back of the reels runs at a fast speed and deposits the straw upon the rack below.

The straw rack is divided at the center and operated by a centrally located crank the outer ends of which are secured on rocker arms that give them a convex motion.

Grain conveyors located under the racks convey the grain to the forward end of the shoe. As the straw is thrown against the grate at the rear of the cylinder, the pickers suddenly change the direction of the straw at right angles, which has a tendency to leave the kernels to fall to the rack below. Should any grain be caught and passed up with the straw it will be subjected to the action of the reels and picker that will again loosen and pull it apart. The reels run rather slowly and confine the straw between them while the picker running at a high rate of speed near to them will pull the straw apart as fast as presented to it. This picker also deposits the straw upon the vibrating rack below in a loose and open condition to permit the kernels to fall out by the action of the rack as it passes over them.

The straw rack has rigidly secured pieces with their upper sides notched to assist the progress of the straw.

The chaffer is link supported on the lower end of the same arm that carries the rear end of the straw rack, and receives the same number of vibrations though not as long a stroke.

After the grain falls through the chaffer it is delivered to a series of corrugated rollers to be further cleaned of any remaining sticks or chaff.

The blast through the chaffer and rollers is produced by an under blast fan delivering into an upper and lower air passage. The upper passage opening under the chaffer, and the lower one leading to the cor- 


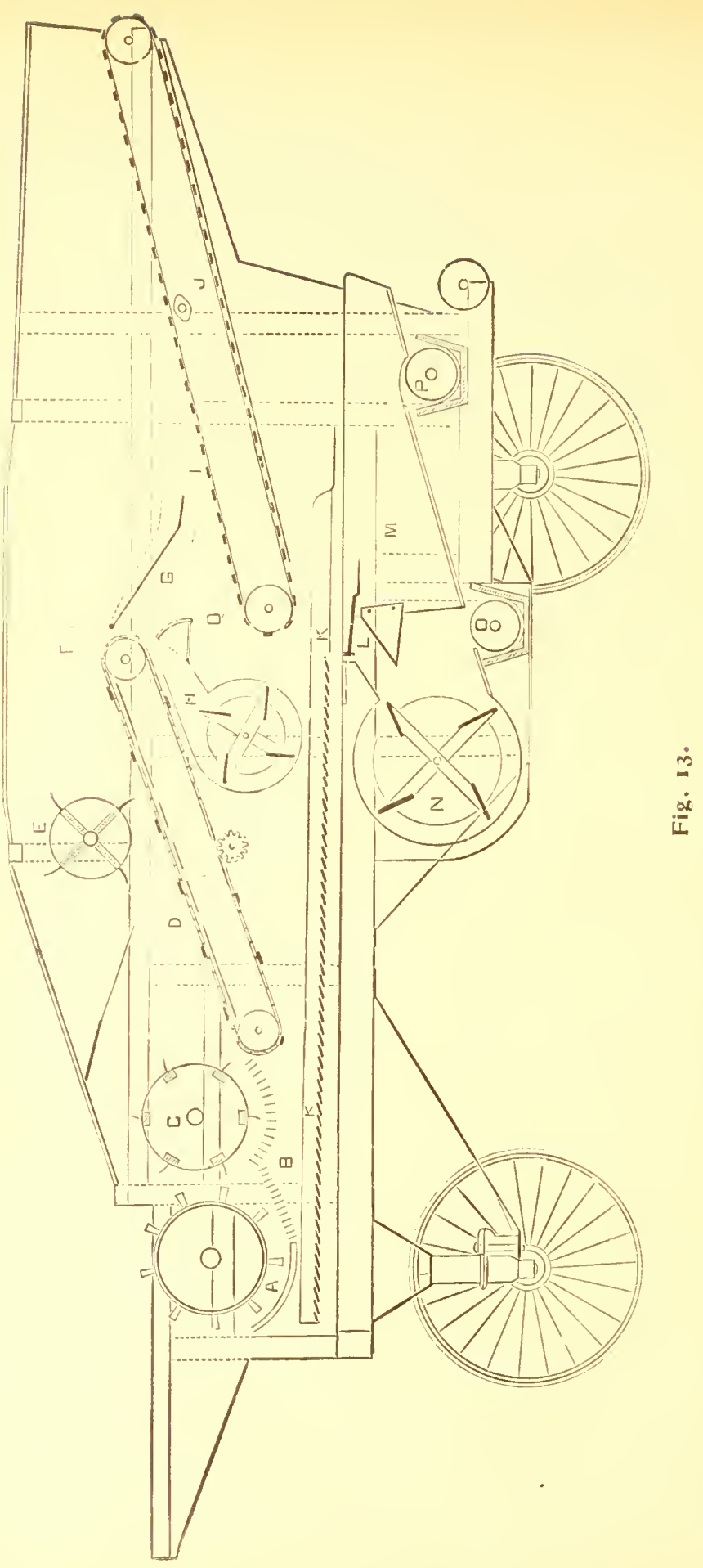


rugated rollers. These rollers are made to revolve slowly while a stationary notched comb is stationed near to each of them. The grain falls between the corrugations of the roller and comb, against the motion of the roller, which tends to lift the chaff and sticks up, and they are blown back to the tailing spout by the blast.

The blast is automatically controlled by a yielding blast board, supported by a spring.

The fan is suspended in a drum sufficiently large to allow the air to discharge clear around its circumference, thus increasing its capacity.

\section{Figure 13.}

Fig. I 3 illustrates very clearly the plan of separation employing traveling raddles or straw rakes, in connection with a separating drum located at the rear of the cylinder, and pineumatic or air blast arranged midway between the raddles, an underblast fan, and 9 -bar cylinder.

In operation the cylinder A delivers the straw and grain against a revolving drum $\mathrm{C}$ that is filled with short spikes which catch the straw and carry it rapidly back over the grate 13 which is made of strap iron. The straw is then delivered on to the traveling raddle $\mathrm{D}$; as it passes up it is acted upon by the beater E. On reaching the upper end of the raddle $\mathrm{D}$ it is loosened up by the picker $\mathrm{F}$, and delivered on to the vibrating fingers $G$ through which a blast of air is being forced by the upper fan $\mathrm{H}$.

The second raddle $I$ then takes the straw and carries it to the rear end of the machine This raddle is vibrated in its travel by passing over the irregular shaped pulley J.

It will thus be seen that the straw and grain are subjected to several novel operations in their course from the cylinder to their destination calculdted to induce separation.

The grain from the forward part of the machine is carried to the shoe $\mathrm{M}$ by the grain conveyor $\mathrm{K} \mathrm{K}$, while that from the rear raddle is returned on a tight bottom by the action of the slats on the lower side. Both deliver on to the distributing grain board $\mathrm{L}$, from whence the grain passes to the sieves where it is acted upon by the blast from the fan $\mathrm{N}$.

$\mathrm{O}$ and $\mathrm{P}$ are the grain and tailings augers. 







\section{FiguRE 14 .}

This cut is designed to show the combination of the vibrating rack and the raddle as a separating device.

The cylinder A, throws the straw against the fingers B located beneath the beater, which deflects it upward, permitting the grain to fall through to the vibrating rack below which has a closed bottom. The vibrating rack has notched pieces running lengthwise to hold up the straw and assist in carrying it along. It also has rearwardly ininclining fingers secured to it which further aid in agitating the straw as it passes over them. The rear portion of the rack terminates in a riser that delivers the straw direct to the raddle, which is vibrated in its center by the square shaped pulley over which it runs.

The conveyor sieve and straw rack are dependent of each other, and are operated by a double crank at the front end of the machine These cranks being set opposite to each other tend to cause the vibrating parts to balance, thus aiding in holding the machine still while at work.

The raddle being set on an incline, has a tendency by its rapid motion to give the lower stalks of the straw a sudden jerk or pull as it leaves the end of the rack tending to pull the column of straw apart, which will permit any imprisoned kernels to fall out, the raddle being long enough to give them ample time to descend before they reach the upper end. The rack and conveyor being link supported have a concave motion. 


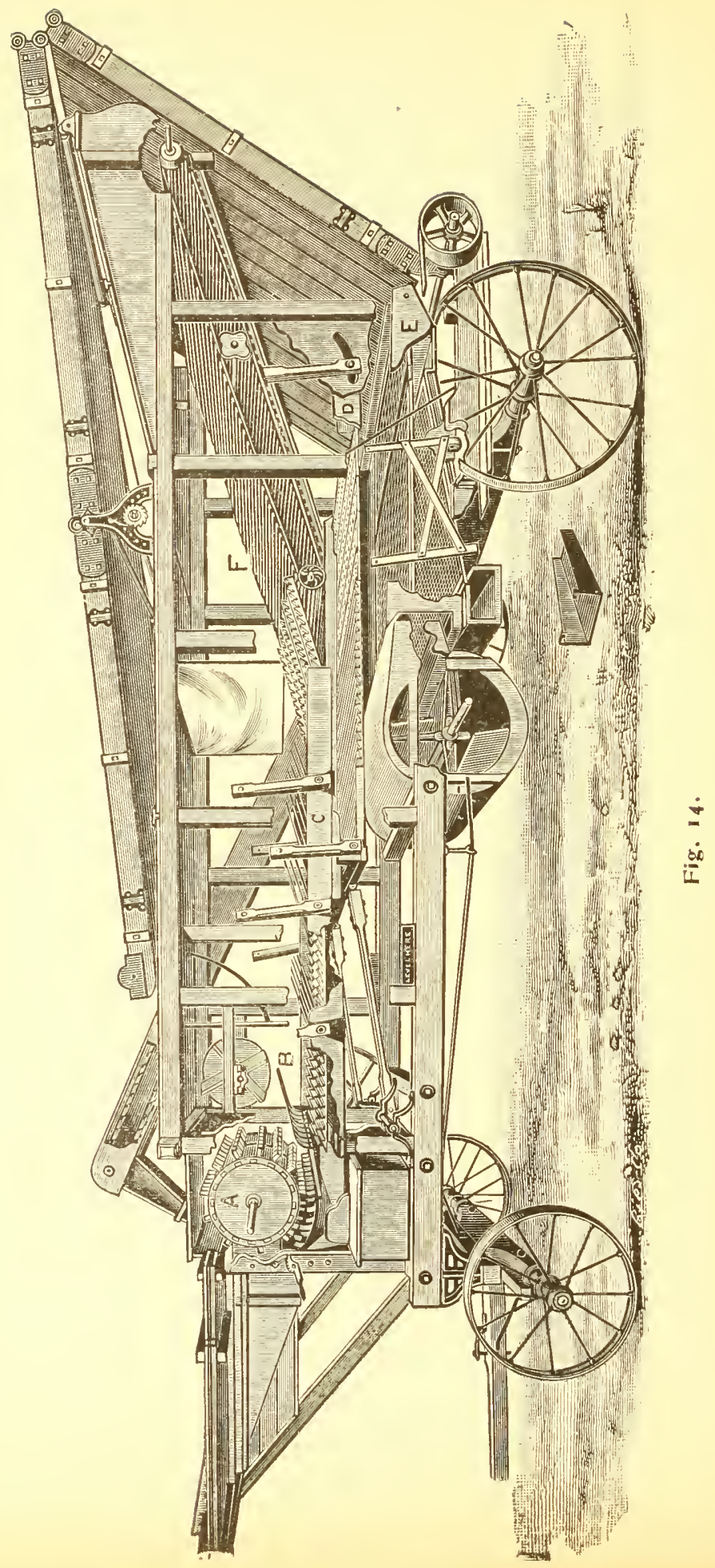




\section{Figure 15.}

Fig. 15, shows another combination of raddles, racks and separating grates, over which forks are made to pass to carry the straw up and back.

An enlarged view of these grates and forks are shown in Fig. 3. This grate located just back of the cylinder catches all the straw and flying kernels. The forks are operated by a crank and link connection giving the lower ends a pointed elliptical motion that cleans the grates at each revolution, permitting the loosened kernels to fall through to the conveyor below. These forks should run quite fast and pass as close to the grates as possible, to insure their being cleaned at each stroke.

As the straw leaves the forks it is deposited on the first table which is composed of parallel notched strips running lengthwise quite a distance apart, the spaces being wide enough to permit a part of the straw to fall through to the second rack below.

It is thus held apart and agitated in this condition by the movement of the rack, then passed along to the rear of the second or lower rack that further moves the straws among themselves by passing them over the fish back risers and letting them fall to the fast moving raddle below. This raddle is vibrated in its center by means of a revolving shaft on which is placed at each end two small pulleys that strike the web alternately as it rises and falls. This shaft to be most effective should be timed so that the pulleys will strike the web at half their height of revolution and their stroke should not be long enough to cause the straw and web to ascend very high as it will have a tendency to throw the grain and not give it time to fall before reaching the rear end.

It will be seen that the straw in its travel from the cylinder to the rear of the machine is subjected to many different motions and combinations calculated to induce separation. 


\section{Self Feeders.}

Self-feeders are of comparatively recent development, though they have been experimented with for several years. After patient study and many unsuccessful trials, the feeder and band cutter has reached a degree of perfection that makes it a desirable part of the complete threshing rig.

The office of the self-feeder is to cut the bands, loosen the bundle, dividing it in a sufficiently thin body, and present it to the cylinder in a manner that will not permit slugging or choking of the cylinder. To do this successfully it is necessary that the bundles should be drawn out or elongated endwise, or divided in some way that the cylinder may not receive the whole bundle at one time. The usual method of accomplishing this is to pass the lower part of the bundle towards the cylinder slowly while the top part has its speed increased by some faster travel. ing mechanism above it, forcing the top straws ahead, while the lower ones are being retarded and this must be accomplished before the bundle reaches the cylinder. The more thorough this is done the better the feeder and the machine seem to work.

There has been some experimenting with governors to regulate the amount being fed to the machine and they are being used with more or less succcess. Some depend on the speed of the cylinder to disengage a mechanism whereby the feeder is thrown out of gear when the speed is reduced below a predetermined number of revolutions per minute. Others regulate by the amount or bulk of the traveling column of straw.

The bundles in most feeders are first deposited on the carrier, on which they are carried along to the band cutting device by means of a raddle constructed of belting with laterally secured slats, or canvas covered table. As the bundles move towards the cylinder, they are acted upon by the band cutters, which should be sufficiently near together and travel closely enough to the table, to insure all the bands being cut. It is also necessary that the bundles should be throughly picked 
apart and loosened up before reaching the cylinder. The band cutters in most of the feeders perform this office also, by passing the knives rapidly into the bundle among the straws in such a manner as to throw the top straws ahead toward the cylinder.

A separator with a properly constructed self-feeder will require but very little more power to thresh the same amount of grain in the same time, as it divides up the bundles and feeds clear across the cylinder much better than is done by hand. But with the use of self-feeders the pitchers usually pass the bundles along a little faster because they do not have to use the same caution about placing them on the table as they do in hand feeding. The only thing they need to observe is the amount or quantity being handled. 


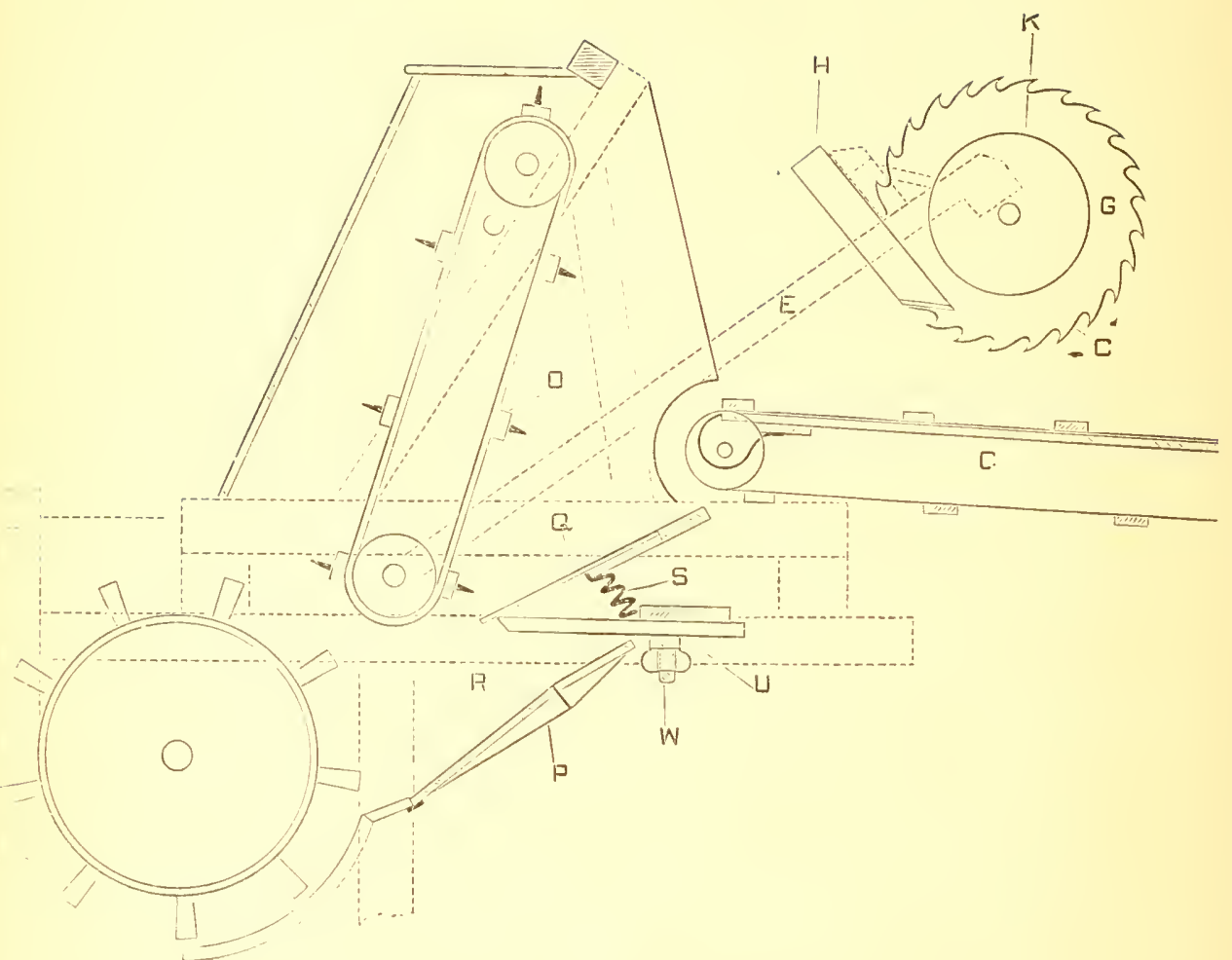

Fig. 16. 


\section{Figure 16.}

Fig. I6 represents one plan of Self-feeder and band cutter, and shows the arrangement of the different parts from which its working may be easily understood.

The bundles are placed on the carrier C; as they pass under the disc $G$ the bands are caught up by the notched teeth and forced against the lower end of the cutting knives $\mathrm{H}$. The frame $\mathrm{E}$ is hinged so the disc head may adjust itself to the thickness of the traveling sheaves as they pass under it. The bundle carrier delivers the grain on to the retaining board $\mathrm{Q}$ which is supported by the coil spring $\mathrm{S}$.

The lower portion of the retaining board is slotted to permit the fingers $\mathrm{R}$ to project through, when the board is depressed by the grain being pressed against it by the traveling rake $\mathrm{O}$, which takes the straw from the board $Q$ and delivers it on to the feed board $P$ where it passes into the cylinder.

Instead of the discs $\mathrm{G}$ cutting the bands they serve only as pickers to pick up the bands and press them against the stationary knives $\mathrm{H}$. There are enough discs and knives arranged across the carrier to prevent the possibility of any bundles passing between and not have their bands cut.

The distance between the front end of the carrier and the traveling rake $\mathrm{O}$, forms a reservoir in which to hold a quantity of grain. The yielding board $Q$, having the office of pressing it against the rake which only takes off a given portion, it being the amount the length of the teeth will grasp and move.

Should the quantity of grain become excessive, the yielding board Q will be depressed and a connecting mechanism throws the carrier out of gear and stops its travel until said board reaches its normal position again.

The size of the throat may be varied by sliding the fingers $\mathrm{R}$, and retained in position by the thumb nut $\mathrm{W}$ and washer $\mathrm{U}$. 


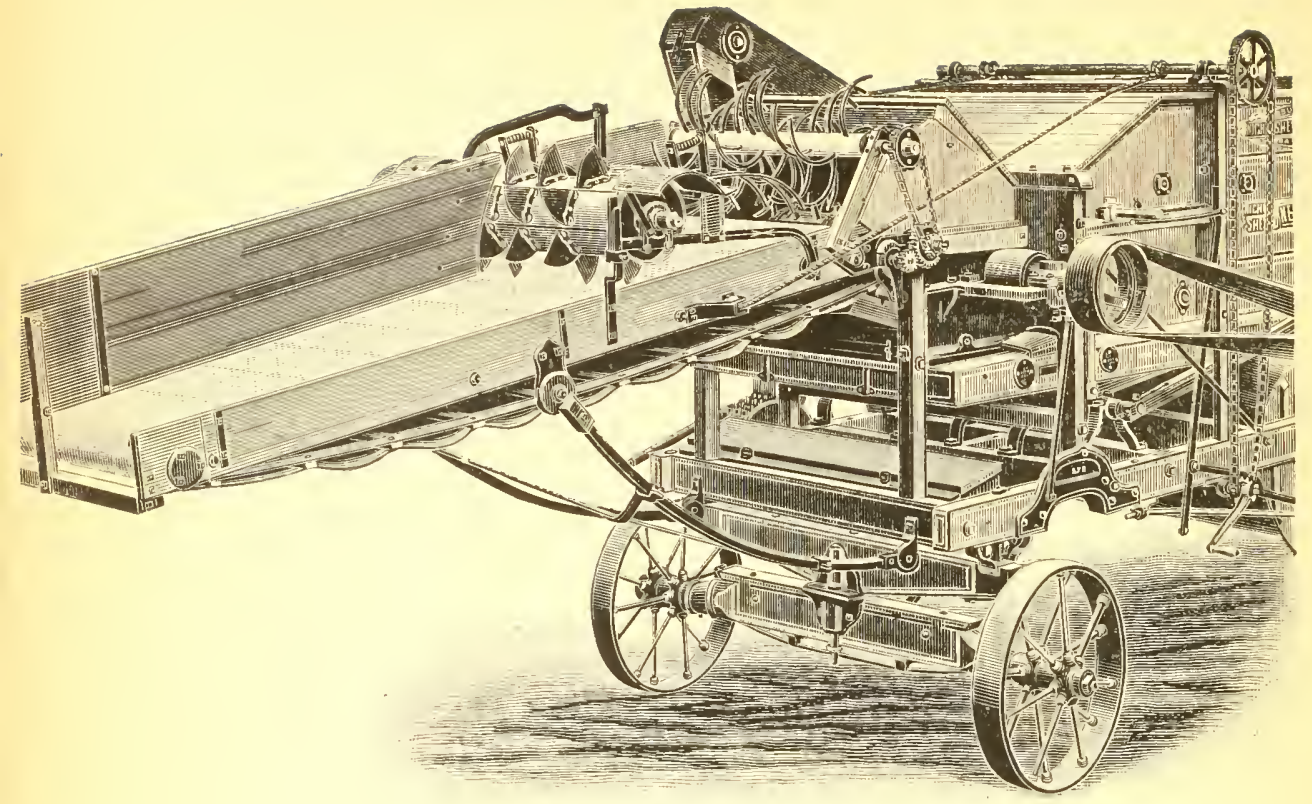

Fig. I 7.

\section{Figure 17.}

In Fig. I7 the bundles are carried on a canvas covered raddle or table to the band cutters and cylinder. The bands are cut by passing the bundles under a revolving drum on which are fastened sharp knives that cut the bands, and at the same time loosen the bundle by pulling it apart, and throwing it towards the regulator placed near the cylinder. This regulator is a centrally located drum in which are fastened curved teeth or fingers.

It revolves quite slowly, the lower side going towards the cylinder. The loosened straw is caught by the curved forks and held from entering the cylinder too fast. The amount is determined by the speed of the regulator.

The frame carrying the band cutting drum may be hinged to rise as it passes over an abnormally large bundle or mass of straw.

The cut shows the feeder in position for work. For moving on the road it is loaded on top of the separator by means of a windlass at. tached to the legs of the feeder. 


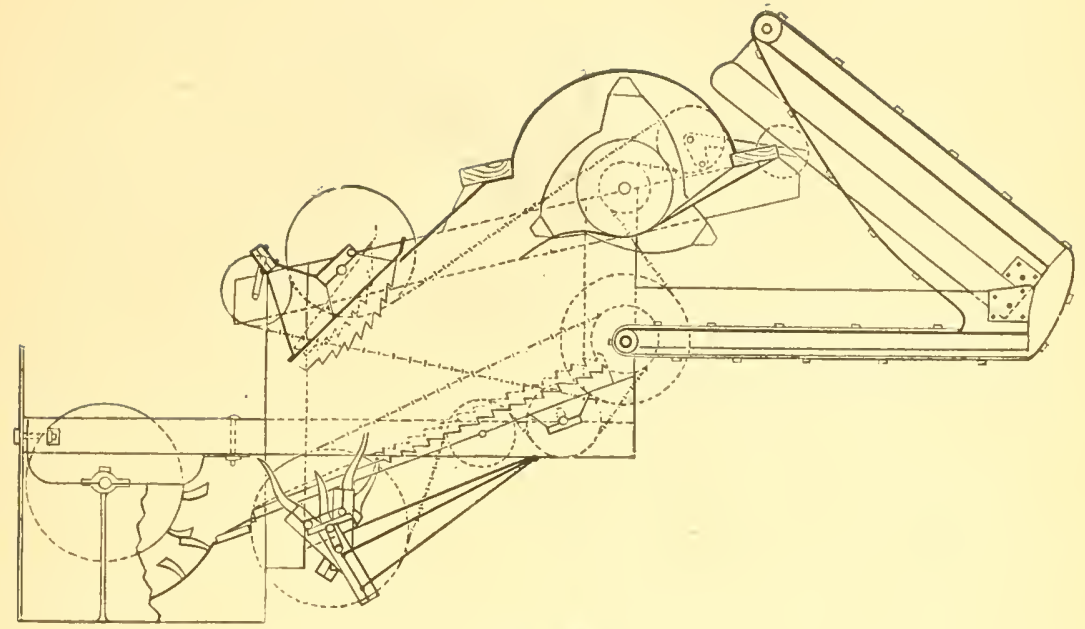

Fig. 18.

\section{Figure 18.}

In Fig. I 8 the bundles are carried by a raddle composed of belting with laterally secured slats. The revolving band cutter is formed of a series of three pointed discs that cut the bands and loosen up the bundles as they pass under it.

The loosened straw is dropped on to the vibrating table or feed board in front of the cylinder. A number of regulating fingers project through the feed board to check the speed of the lower side of the ingoing grain. Short vibrating deflectors are operated above tending to force the top part of the mass of straw into the cylinder, while the lower part is being retained by the regulating fingers below, thus tending to prevent slugging by not admitting too much straw at one time. 


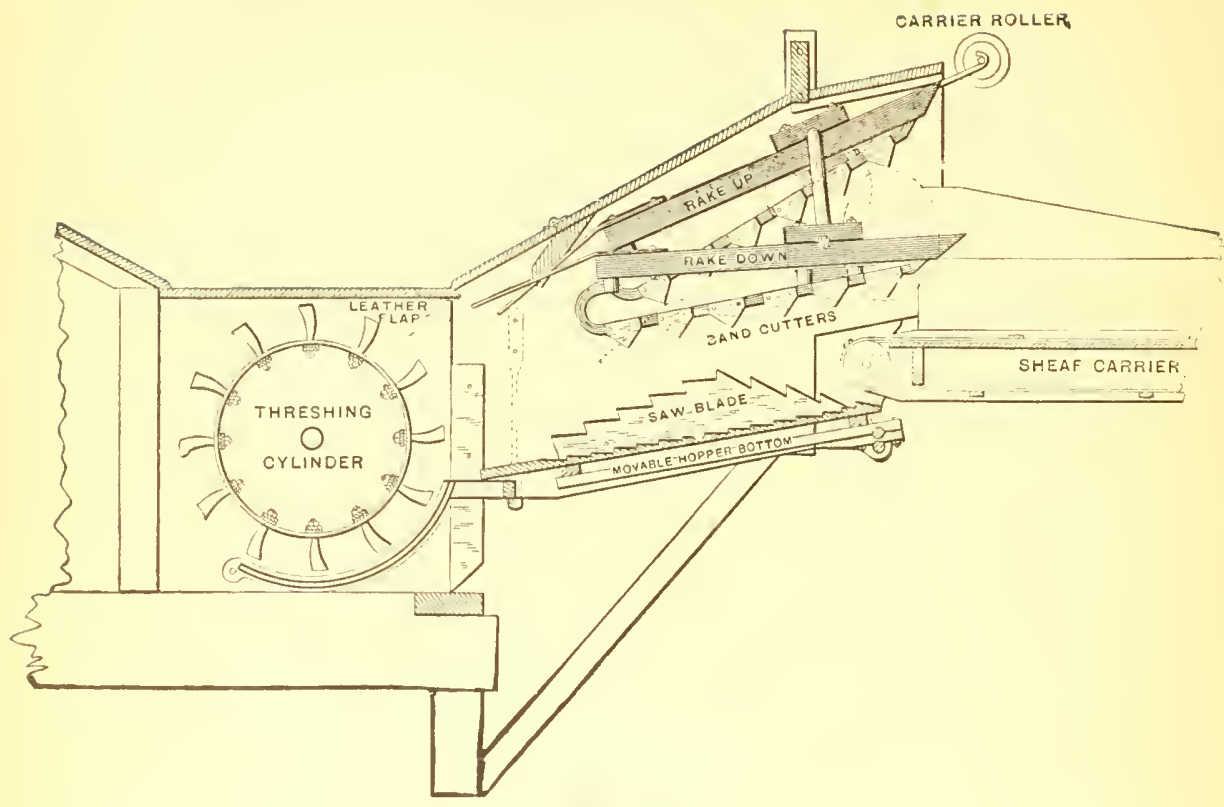

Fig. 19.

\section{Figure 19.}

Fig. I9 represents a class called crank feeders.

The bundles are placed on the sheaf carrier which deposits them on the oscillating bottom or feed board where they are acted upon by the band cutting knives above. The knives are operated by a multiple crank which gives the forward part of the bars holding the knives a circular motion, and the rear end an angular parallel motion. This action cuts the bands and tends to elongate the bundle towards the cylinder; the notched pieces below tending to retard the bottom portion of the grain somewhat, while the knives cut and loosen from above.

The cranks are constructed so the knife bars balance, as they revolve, by being set opposite each other. 


\section{Feeding.}

The separator, to work in harmony with the engine should be fed uniformly, keeping a continuous flow of straw through the cylinder at all times. This keeps the engine working with a uniform amount of steam and given tension on the belt.

When grain is passed into the cylinder it tends to check its speed. As soon as this checking is felt on the main drive belt it also slows the speed of the engine until the governor has time to act and let on more steam, which brings the motion back to its normal speed. This it does by pulling harder on the drive belt. Now if while pulling hard, the cylinder suddenly runs empty of straw, the speed at once increases in obedience to the extra tension on the belt, as it takes a little time to communicate this change of speed to the governor and have it act upon the steam. The result is a see sawing of motion every time a bundle goes in if it is not properly divided up and lapped on to the next one. This is true both in hand and self-feeding. A whole or compact bundle large enough to slug should not be permitted to enter the cylinder.

The cylinder teeth are about three inches long. The concave teeth occupy about one third of the space between the cylinder bars and concave, this leaves a space of about two inches which the bundle must be compressed into in passing through. This compressing process by the teeth consumes a large amount of power.

A 500 pound cylinder running at full speed, has a momentum or striking force of 1320 tons. This indicates the terrible strain brought to bear when a bundle goes in sufficiently large to stop the cylinder dead still at once, though this does not often happen. But the power consumed when the bundles are not properly divided up is enormous. This is more so in damp and tough grain than when dryer, as the damp straw being tougher and more pliable clings firmer to the teeth. 


\section{Wind Stackers.}

It might be said of pneumatic or wind stackers that they are just in the process of being developed and introduced. In some sections of the country they have come into quite common use while in others they have not been tried so generally.

Though there have been pneumatic straw handling machines in use to a limited extent for several years, especially in Europe where they were first tried, it is only recently that they have reached a degree of perfection to warrant their general use. One of the greatest obstacles to overcome has been the great amount of power required to run them, but that has been remedied to a certain extent though it is one of the chief items to be considered in their use at the present time.

It is difficult to state the actual horse power required to drive them; but the comparative amount may be arrived at by the width of belt and size of pulley used to convey the motion to them. If the belt is as wide and the pulley as large which runs the stacker as that which runs the separator and both belts of equal tightness it is reasonable to suppose they consume an equal amount of power. Or if the belt coming from the engine is a 7 inch belt and running on an 8 inch pulley, and the belt which runs the wind stacker a 4 inch belt running on a pulley of the same size, and both belts of the same tension and both working to their full capacity it is plain then the wind stacker is using 4-7 of the power transmitted by the engine. If the latter belt was 5 inches then 5-7 of the power would be used to drive it.

The wind stacker has some advantages peculiar to itself. It does not require any extra effort to set it as the swinging stacker does, when commencing a new setting of stacks, or in moving the machine after the stacks are finished. It will throw the straw farther, which makes it less liable to fill up near it and cause trouble.

In the first wind stackers used the fan was located beneath the straw exit and forced a blast into the straw pipe, which was funnel 
shaped at the point where the straw and blast entered. The difficulty with this style was, that a slight obstruction would cause the straw to stop in the pipe and the air would return and blow out at the point where the straw entered, not being able to maintain pressure enough to cause the straw to continue its course under all conditions to the end of the pipe. In the present construction the straw enters the fan with the blast and is forced to travel the whole length of the pipe before finding an outlet. A sufficiently strong pressure is thus maintained to cause the continual How of the blast and straw; this pressure to insure successful work should be equal to the weight of a column of water about 3 inches high and does not need to travel very fast, but when being retarded by wet or heavy straw should come with a force equal to the above. There is a difference between force and speed. The one that has the most force and least speed will be the one that operates best and requires least power to run.

\section{Handling The Threshed Grain.}

There is a variety of weighers, measurers, sackers, and wagon loaders on the market and in use for handling cleaned grain as it comes from the machine. They do not need more than passing notice here.

First is the class that weighs the grain, and registers the number of bushels delivered. Also the wagon loader that delivers to either side of the machine without any device for recording the amount handled.

There are also those that measure the grain instead of weighing it, keeping a record of the amount on a suitably arranged tallier. The common short sacker is also a very handy and common means of getting the grain sacked, requiring one man to operate it.

The old way of measuring with half bushels from the ground is a laborious task when threshing very fast. 


\section{Operation.}

In operation, the threshing machine, the same as any other machine, will do the best work when properly managed.

There is no machine whose work is more varied nor which is required to be operated under so many different conditions.

Scarcely two fields of grain have grown, ripened and been cut and handled the same. One may be in a condition to shell from the straw easily, while in another the kernels may cling to the chaff or heads so as to make it almost impossible to dislodge them. One stack of grain may be brittle and cut up, another may pass through without breaking up much. One kind may be stiff and stubborn, another soft and pliable. One lot may have many blades or leaves on the stalks, another only the plain stalk and head. One kind may have a light fluffy chaff and dense heavy kernels, another, with the chaff heavy and filled with sap and the kernel as light as the chaff. Some fields are filled with weeds and foreign matter which the machine is expected to distinguish and separate from the grain.

Then again some conditions require more power than others to drive the machine. Some days are bright and sunshiny, others damp and foggy. Some warm or hot, others cold. There may be a hard wind blowing or none at all, each condition affecting the machine in a different way. The experienced Operator is expected to meet all these varied conditions and save every kernel, and clean the grain perfectly, and do many other things well nigh impossible. But the man who understands the machine and its workings best, will come the nearest to perfection in the operation of the same.

The Cylinder should receive special attention and be kept in good condition. If it is too much out of balance it should be taken from the machine and set on straight edges and put in balance again by inserting counterbalancing weights on the light side. The boxes should not be run too tight as it consumes a large amount of power to overcome the extra friction.

The teeth should not be permitted to become so worn and rounded as to retard the straw from entering the cylinder freely. Part new teeth divided equally around and along the cylinder, will assist in the suction of the straw, and thresh clean also. 
Care should be used to keep the teeth properly spaced, any bent ones may be trued up with the tooth straightener or with a heavy hammer.

The cracking of grain is usually caused by one or more teeth running so near the concave teeth or bottom as not to permit a whole kernel to pass and by being wedged between them the kernel is cracked or broken. Still there is another cause of cracking grain, by being repeatedly returned to the cylinder by the tailings elevator. Each time the kernel receives a blow from the moving tooth it is partly disintegrated and soon is forced open or broken to pieces.

Only sufficient concave teeth should be used to retard the straw long enough in its passage through the cylinder to allow all the kernels to be lcosened, as more consume unnecessary power and cut up the straw to such an extent as to interfere with the proper functions of the separating and cleaning devices. The machine will often do better work with two or four rows of concave teeth than with more. In oats two rows are usually sufficient except sometimes where the kernel is small and light and the oats having, been cut green seem to be tough and cling to the straw, then a high speed of the cylinder and more concave teeth are necessary to loosen all of them from the straw.

In sections where flax is grown it is a good plan to have a concave especially designed, with the teeth closer together, as some conditions need very close work to break open the balls containing the seed.

There is a condition of flax quite often found where the ball is saturated with an oily gummy substance that causes it to be very tough and hard to open, and it is liable to break off from the stalk and pass through the machine in a whole condition. In such cases use all the concave teeth possible and run the cylinder at high speed and arrange the rear end of the machine to return the unbroken balls through the tailings elevator.

In threshing barley it "nubs" or breaks off the beard better with plenty of concave teeth in, and running at high speed.

The grate back of the concave should be raised at the rear side enough to permit the straw and grain, as it comes from the cylinder, to strike its face at a slight angle. This will keep it clean and prevent it from loading up in dry and brittle straw.

The beater should be in a position for the straw to pass it without 
changing the course of the straw too much, that is, it should be in such a position that the straw coming from the cylinder will not strike it near the center, as it would then have to change its course to pass under or over the beater, which ever the case may be.

When the straw passes under, the beater should be only low enough to reach the straw sufficiently to keep it moving.

In the scheme of separation the first essential feature is to have the cylinder leave the straw as near whole as possible and have it threshed clean of kernels. The nearer whole the stalks are the more freely will the kernels fall out, as it will not pack together so much as if cut and broken up.

In some cases the stalks are heavily loaded with leaves that break loose and cut up forming a homogeneous mass in which the kernels are lodged and retained.

Oats in some cases are difficult to separate. In some sections of the country the rust forms on the stalks and leaves before being harvested. It usually leaves them very brittle, and the kernels blight making them light. The rust on the stalks has a certain clinging roughness that makes them adhere to each other, and tends to retard the action of the rack or raddle in moving them about among each other, they having a tendency to move along in a continuous mass. In such cases all that can be done is to adjust the machine to best advantage, run with a full motion and regulate the amount being fed accordingly.

In threshing rye, which is usually very easily separated on account of the stalks being stiff, comparatively little chaff and leaves are found to retard separation. In some cases the straw is so fluffy and loose as to prevent it being worked back fast enough by the separating devices causing the body of the machine to choke and fill up. This may be remedied somewhat by inserting more concave teeth to cut the straw up.

The check board in vibrating machines can sometimes be weighted to advantage which has a tendency to pound the straw down and compress it, giving the table a better chance to handle it. The check board can be weighted by fastening a piece of wood or iron to its back and upper side running it lengthwise and securing it by bolts or screws.

As has been stated before, it is quite essential to the good working 
of a separator that it should stand quite still on its trucks while in operation.

There is a great difference whether the separator frame is still, and the moving parts make their full motion, or the frame does half or even a part of the moving and the working parts only go far enough to complete the motion.

There have been several devices used to hold the machine still on its trucks. Manufacturers seem to have neglected to properly provide means for that purpose. Some use blocks driven under the wheels but they are unsatisfactory as they work loose and do not hold properly.

Some use a brace running from the sill to the lower part of the truck wheel held by a properly constructed clamp bolt. Other clamps and braces have been devised for this purpose.

There is also another reason why the separator should stand still. When the engine is working it has one side of the belt drawn up tight while the other side is comparatively loose. The harder it is working the tighter this will be drawn. Now if the separator is rocking back and forth on its trucks, as it goes toward the engine it takes up more slack, and when moving backward away from the engine the belt will either have to stretch, or slip upon the pulley, and as the slack has already been taken up and the belt drawn tight it is very liable to do the latter. This is hard upon the drive belt and the lagging of the pulley and a great waste of power. This is augmented and made worse if the engine is also permitted to rock and vibrate. For the vibrations of the two will not be the same, and during part of the time in the series of oscillations, the separator will be moving in one direction and the engine in the other, thus doubly increasing the liability of the belt to slip.

If it is a horse power machine the same reasons exist for needing the separator to stand quiet as it causes a heavy strain on the tumbling rods that convey the power to the separator.

If the separator fails to take the grain out of the straw properly it is very likely because of one or more of the following reasons; viz., the separator is not standing still upon its trucks; it is not running at the proper speed, the cylinder fails to dislodge all of the kernels; the rear end is standing too high, or the machine is being crowded beyond its natural capacity.

The speed of the machine is quite important.

One of the stubborn 
facts in threshing is, that the time when a good stiff motion is needed is the time when the machine is being fed hard and is very liable to be the time when the motion is low. This is more especially true when the source of power is weak or being taxed to its full limit.

The Shoe or cleaning mill should receive special study by any one who intends to make threshing a success. Though a very simple appearing device it has many features that are not generally understood. The large variety of arrangements of the different parts prevents this work from going into the details of every machine, but it will deal with them in a general way that is applicable to all.

The motion of the shoe is varied in the different machines, in some as short as 5-8 of an inch, up to 4 inches in others, though there is not so much difference in the motion of the upper sieve or chaffer. In most machines it is from 2 to 3 inches. The following rule will be found nearly correct, viz., the shorter the stroke the more vibrations per minute, the longer the stroke the less the number of vibrations per minute.

The speed should be only strong and quick enough to throw the grain but slightly at the top finish of the stroke, if more than this, it is too strong and will carry or throw the grain and a part of it will pass out with the chaff. If the motion is not strong enough to cause the grain to leave the upper surface of the sieve slightly at each stroke the result is, the meshes become filled with grain and chaff, the sieve or chaffer becomes choked and loaded up to such an extent as to allow but very little to pass through If the mechanism is such that the upper part of the stroke is the more strong and quick leaving the lower end of the stroke slow and mild, all the better; as the upper part will do the throwing and agitating while the slow part of the stroke will give the sieve time to come to rest for an instant permitting the kernels to fall through much better.

The boxes and connections that operate the shoe should be kept in good order and not be permitted to get loose as the loss of motion causes a pounding that jars the sieve causing it to spring and tremble, greatly interfering with the free passage of the kernels.

The Blast should come in for its share of attention. Much depends upon it to accomplish good work and when once mastered and controlled it is a very obedient servant. But few changes have been 
adopted in the construction of the fans since they were first used in the separators. They have faults as well as virtues; they do not always send the proper amount of blast just where intended or needed most.

There is a great difference in the condition of the material coming to the shoe to be handled at different times, and in different sections of the country. In parts of the country where spring wheat is raised there is much more work required of the shoe, there being more chaff; and the straw being stiffer and harder to thresh breaks up much more than that of the variety known as winter wheat raised in other sections.

The chaff and dust from spring wheat is much denser and heavier than that from winter wheat, requiring more than twice the pressure of blast to lift and penetrate through it though the kernels are not much heavier.

The cylinder and concaves should be adjusted to cut the straw up as little as possible and get the grain out, by doing so it will be made easier for the shoe to do its work.

As the grain and chaff are delivered to the front end of the chaffer they are more or less mixed, the kernels being intermingled with the chaff, and of a depth and quantity according to the amount being threshed.

It is plain that so long as the chaff and kernels are mixed together, if the meshes of the chaffer are not large enough to let the whole mass of mixed material drop through, the most of it will be carried along by the action of the chaffer to the rear end. But force a little blast through and notice the effect; as the blast comes through the meshes of the sieve it lifts grain, straw and all. Now the kernels at or near the bottom of the mass will fall by their own weight to or through the sieve. As the blast continues to find its way through and among the various particles of the mass it loosens and separates it carrying the lightest up first and farthest leaving the heavier pieces and kernels to fall by their weight.

By watching the blast at work passing through the chaff it will be noticed that the particles traveling through the air are entirely free from each other, each one trying to get as far away from its neighbor as possible. There are never any bunches clinging together being blown up by the action of the air, but they are always separated, producing the very best conditions for the separation of the kernels from the chaff to take place. 
The blast should be strong enough at the very front of the chaffer to insure it always flowing through the very first meshes enough to keep them cleared, and passing up through the column of chaff as it passes along; but it should not blow fast enough to lift the light kernels very high. There is a difference between strength and speed. The blast should have strength but not much speed. A horse might be very strong and able to move a heavy load but not move it very fast. The horse would be able to go at a uniform speed whether loaded heavy or light. So with the blast in the shoe, it should be able to move at its regular speed regardless of the amount of grain and chaff to be handled.

It is plain that it should be the strongest at the front end of the chaffer where the load is heaviest, the chaff being mixed with the grain and packed together at that point. After the blast has once penetrated through the column and has the chaff lifted up in the air it does not need as strong a blast to keep it there. In some wrongly constructed shoes the reverse is found; the blast being the strongest at the rear end and the weakest at the front end of the chaffer. In such cases the heavier the load of chaff coming on at the front end the harder the blast will be at the rear. As soon as a little too much grain and chaff enter the front end of the chaffer and load the meshes enough, the blast ceases to escape there and is forced along to the rear end and being confined there and deflected up by the bottom of the shoe it is blown out through the rear meshes of the sieve with force enough to carry kernels and all along with it.

If a shoe is found to be in this condition the remedy is to arrange and adjust the blast or deflecting boards in such a manner as to cause the blast to strike the front end more forcibly.

To aid in this adjustment it would be well to consider first some of the peculiarities of the fan and its action on the air. As it revolves the wings cause the air to revolve with it. As each wing passes the outlet a small portion of the air is thrown off by centrifugal force, other air coming in through the openings at the end to take its place in the fan.

As the fan revolves the front side of the wing has a slight increase of pressure of air against it, while the back side has a corresponding decreased pressure. The sum of these minus and plus sides being very nearly equal to the natural atmospheric pressure. 
As each wing passes the outlet opening into the shoe the air starts to rush in behind the wing, from the shoe, to fill the partial vacuum on the rear side of the fan wing. A small portion enters the fan after each wing; the next wing coming has a tendency to force it back again before it has entered very far. This causes the air to be moved first one way, then the other, causing the low vibrating or humming sound heard in fast running fans. Now this action of the air is not equal and alike along the entire length of the wing. The most air being forced out at the center of the shoe materially effects the action of the blast through the sieves.

When the fan is in motion, with the ends open free to admit air, it rushes in from both ends and these two columns of air meet midway, at the center of the fan. The meeting of these two columns increases the pressure somewhat at this central point and to relieve this pressure it is passed off most freely in the outlet toward the sieves at the center. As the wing passes the outlet the most air rushes in behind the wing at the ends, as the vacuum is greater there than at the center of the wing; consequently instead of the air blowing from the fan toward the sieves, it passes from the sieves into the fan near the ends of the wings. This is more so in wide machines than in narrow ones as this fact is more marked in long than in comparatively short fans.

There is still another reason for this unrecognized phenomenon. As the air rushes in at the ends of the fan, toward its center, it has but very little pressure sideways toward the sieves and the extra pressure in the shoe forces the air back into the fan, thus causing the air to travel the wrong way a part of the distance near the ends of the wings, as the air comes from the center of the fan a part of it swings around and passes back into the fan at the ends. This causes a kind of an eddy or whirling motion. Should this effect become strong enough the result will be to carrysome of the falling grain along with the air into the fan.

In some machines the corners of the wings are worn by striking against the grain that is carried into it by the action of the air. This also effects the perfect cleaning, as at the front corners of the sieves the blast has a tendency downward carrying the chaff and dust with it into the grain.

This whirling motion can be tested in any machine by taking the sieves out and running the machine empty. While in motion take a 
cane or stick of convenient length and fasten a ribbon about four or five inches long to one end. By holding this near the fan at the outlet the ribbon will indicate which way the blast is moving.

It will be found that the direction of the blast is not in a direct line from the point of delivery of the fan along the stationary blast board at the top or bottom toward the sieves, but rather has a tendency to follow the curve of the fan until it comes in contact with the blast board. Further, in the underblast fan the blast does not leave the fan at the bottom and travel in a direct line along the bottom blast board toward the sieves; but travels in a thin column along near the fan increasing slightly in bulk until it reaches the top blast board where it is deflected downward and backward, the angle of reflection being nearly equal to the angle of incidence.

The air being compressed slightly in the center will take a course angling toward the sides causing it to blow harder at the rear corners than in the center at the rear end.

It will greatly aid the blast to equalize and adjust itself if two or three narrow wind boards $\mathrm{I}$ or 2 inches wide be placed parallel to the fan in the forward part of the shoe below the sieves. They should be set at such an angle as to deflect the blast toward the forward part of the sieves and near enough together to require a little pressure to force the blast through. This will tend to cause the air to pass through along the entire length of the opening to relieve the pressure on the fan side, and will tend to make the blast more uniform across the entire. width of the sieves.

There is a great variety of sieves made and used. In former years the woven wire ones were in general use, but they are not used as much now. They admit the blast too freely and the straws run through the meshes and fill them up. The tendency at present is toward sheet metal ones, being either perforated through the plain surface or cut and bent into irregular shaped lips and corrugations.

Chaffers constructed of wooden slats set at an angle are used, also perforated plain wooden ones with the holes bored at an angle.

The sieves should be constructed and adapted for the kind of work being done.

The frame should not spring very much while in motion as the excessive vibration in the center tends to throw the grain in too positive a manner. The angle of the blast passing through the chaffer should be 
well upward rather than backward. This is accomplished by the position of the lip or slat forming the meshes of the sieve, the blast taking the same angle as the slat or lip of the sieve.

A kernel of grain will fall through a perpendicular blast more readily than through an angular one, and a perpendicular blast will lift the chaff from the sieve much better than an angular one.

The holes or meshes should be only large enough to freely allow the grain to pass through. When the sieve is correctly constructed and the blast properly adjusted there need be no waste and the grain will be well cleaned. When the shoe is working properly there will be very little tailings going back to the cylinder. Tailings is what goes through the chaffer and does not gothrough the sieve and is composed of chaff and grain.

Upon reflection then it will be seen that if the blast strikes every mesh in the chaffer properly it will prevent any chaff from passing through and cause it to be carried off with the straw. Further, if the chaffer is properly constructed and has the right motion, as soon as the blast clears the meshes of chaff the grain will fall through at once at the forward end, and will then have the entire length of the sieve to travel over before reaching the tailings spout thus increasing its chances of passing through and not be carried around with the tailings.

Otherwise if the blast does not pass through the column of chaff until it is half way or more along the sieve, it is plain that a part of the chaff has been sifting through the meshes where no blast was felt. The chaff will then find its exit along the next lower sieve to the tailings spout. A portion of the grain cannot pass through the chaffer at the front end but is carried along with the chaff to the point where the blast first passes through it. This may be so near the tailings spout as to cause the grain to be carried over into the straw or go back to the cylinder with the tailings, thus overloading the elevator and unduly taxing the capacity of the separating and cleaning devices, and if the same kernels should be returned often, the action of the cylinder will tend to crack or hull them as the case may be.

As few sieves should be used as will do the work properly. Oats and wheat usually require only one. In some instances in weedy wheat a second sieve in the shoe will improve the cleaning. Flax, if 
weedy, may be run through two sieves below the chaffer. Many make a mistake by trying to run flax through a sieve with too small meshes causing it to pass over to the tailings spout which greatly interferes with the free action of the blast. Some kinds of flax have a seed much larger than others. In fast flax threshing, much more satisfactory work can be done by using a finishing sieve with the meshes as large as 3-16 of an inch. This refers to perforated sheet metal ones.)

\section{BELTS.}

The success of a machine depends largely upon the working of the belts. Their proper care and management is of importance. The material should be of the best quality.

Leather belts should always be run with the grain or smooth side to the pulley, as they will run easier transmit more power and last longer. They will run easier because the flesh or rough side by being on the outside will expand more easily and adjust itself to the curve in passing around the pulley, which also has a tendency to add to the life of the belt. The smooth side will transmit more power because it brings more surface in contact with the pulley. They should be run only tight enough to perform the work without slipping, for whatever power is consumed in slipping is lost. If a belt is permitted to slip it will have a tendency to partially run off of the pulley, and will also soon wear out the lacings.

If belts become dry and brittle they should have a dressing of neatsfoot oil with a very little resin mixed in it. Do not use enough resin to leave the surface of the belt sticky. A belt that is pliable will transmit more power than if dry and hard.

Rubber belting is also used quite extensively for some purposes, and when of the best grade is very economical as its first cost is less than that of the best grades of leather.

Chain or link belting is used, and in some places is preferable to any other. It never slips or runs off, nor does it ever come unlaced. When link belting is used it should not be run too tight as it causes a trembling or jarring vibration as each link passes on to the sprocket. 


\section{LACING A BELT.}

There is a right and a wrong way to lace a belt. The two ends to be joined should be cut square. A belt punch of sufficient size should be used to permit the lacing to pass through freely without straining the fibre of the leather, which has a tendency to cause the holes to tear out and the lacing to break off. A punch making a hole about 5-16 of an inch is the most convenient size for ordinary work. A smaller one should be used to make a hole in which to fasten the ends of the lacing which should be of a size to permit the lace to pass through tight.

In punching the holes, care should be taken to get the spaces uniform and of equal distance from the edge of the belt. An odd number of holes gives the best results, thus, three, five or seven may be made according to the width of the belt.

The start should be made with the lace by passing the two ends of the lace through the two center holes from the flesh side, to the smooth side. This when finished will leave the ends of the lace projecting on the side to be run next to the pulley, this will prevent the ends from slapping and wearing off as they pass around the pulley's. It will also leave the lace crossed on the pulley side, thus giving more surface for contact. From the center, lace once through each hole until the outer edge is reached using one end of lace for one edge and the other end for the other edge. Then pass the ends of lace through each outside hole again, then through the next succeeding holes until the center is reached using each end of the lace for its respective edge of the belt. Then pass the ends of the lace up through the small retaining holes.

This when finished has the lace passed through each hole twice and is what is called double lacing. The length of the lace should be such as to project through only about three inches when finished. Punch the small retaining hole for end of lace in line with the center holes then when the belt stretches and is cut off to be relaced, it will be in position to be enlarged and used.

Good lace leather should be used and cut of uniform width, about 5-1 6 of an inch, with ends tapered for convenience. In lacing place the smooth or grain side of lace out, as so placed it will last longer.

A lace-cutter is a cheap and convenient tool, and should be found in the kit of tools of every thresherman. 


\section{Babbitting Boxes.}

With a little care and practice any one of ordinary ability can babbitt boxes.

First remove the old babbitt and clean the boxes well, to get them free from grease and dampness as the gases when heated will cause the babbitt to blow ont. Bolt the boxes in place with shimming (pieces of pasteboard) between the halves to allow take up for wear. Hold the shaft in place at the center of the box by inserting a narrow strip of leather around the shaft at the end of the box, then with clay moistened to the consistency of stiff dough thoroughly seal up all openings to prevent the liquid metal from running out. Place a wooden stick in the oil hole and plaster up, leaving the top flaring to pour the metal in. After all is in readiness remove the stick with care to prevent any clay from being broken loose and falling into the box.

In preparing the shimming between the boxes see that the edge of the shimming comes against the shaft, in order to separate the metal in the two halves. Cut two or three small rotches in the shimming about $\frac{1}{3}$ inch deep and $1 / 4$ inch long to allow the baìbitt to run in and fill the lower half of the box.

To be successful the babbitt metal should be at about the temperature to burn a piece of wood To test it insert a stick into the melting metal occasionally, and when it gets hot enough to make the stick smoke or turn black it is of the right temperature. When pouring do not stop until the box is filled as the metal chills very quickly and will not unite when fresh metal is poured in. The metal should be poured in as fast as it will run through the opening to insure its filling the lower half.

If the lower half should not fill properly enlarge the openings in the shimming between the halves of the box and try it again. After pouring, remove the clay and break the box apart by driving a cold chisel between the halves, then dress off the points formed in the notches of the shimming. 
Relieve the shaft a little by scraping some of the babbitt metal away from the inside of the box, removing the most near the inside edges, also put in an extra piece of shimming as the box would be too tight and heat if left as babbitted.

Before babbitting care should be used to have the box bolted down tight, in the position it is intended to run, as the tightening is liable to warp its position and get it out of line.

If a stick is inserted into the oil hole as soon as the metal is poured before it cools, it will form an oil hole and save drilling or punching same out.

Babbitt is made of Block tin and Antimony, the best grades also contain a little copper. Babbitt with zinc in its composition should not be used as it has a tendency to cause the boxes to heat and will not wear long.

\section{LUBRICATION.}

The life of a machine and its ease of operation depend very much upon the manner in which its journals are kept lubricated.

In the selection of lubricants we should keep in mind the purpose for which they are to be used. In hot, dry weather a much thicker and heavier oil can be used than in cold weather. Mineral oils are usually preferred in places subject to heat, in preference to those composed of animal or vegetable matter. Among dealers there has been quite a tendency to supply the cheapest oil, but which in many instances has been the dearest for the user.

There is a tendency at the present time toward what is called hard oil. It is a mineral product from petroleum and certainly has many excellent qualities. It is easily applied and very lasting in its effects. In the use of hard oil, a cup adapted to the purpose must be used. It is usually a cup inserted in the box with cover or cap screwed on, by which means the grease may be forced through the stem into the box. Only a very little of the oil is necessary to lubricate a journal, and is very lasting. 
In many of the machine oils, vegetable matter mixed with kerosene or other light mineral oil is used, and can be sold very cheap. The kerosene soon evaporates at the end of the journal, leaving the vegetable matter in the box, which thickens and gums causing the box to heat, or the shaft to run hard. Oil containing kerosene is also hard on paint where it spreads out upon the wood work causing the varnish to corrode and become dull

A good grade of oil for general purposes is what is called black or crude oil. It is a mineral product with all the light oils removed, and comes in different grades of density. The heavier qualities can be used in warm weather to advantage, while in colder times the lighter grades will be found to run more freely, and not thicken as readily.

\section{Getting Ready.}

If the machine is one that has been in use the year before, it should be put in good condition before the time announced to commence threshing by going over it and seeing that every piece is in proper repair to maintain a fall's run. See that the boxes over the entire machine are properly adjusted and any worn ones set up. If too much worn they should be rebabbitted. A shaft should not be so loose in the box as to permit very much rattling or moving back and forth, though it runs easier to not be too tight.

All boxes where the shaft is compelled to produce or withstand a vibrating motion should be kept in good condition and not be allowed to get loose at any time, as the least play will permit the shaft to pound at each vibrating stroke causing the shaft to wear flat. Neither will it cause the part being oscillated or vibrated to work smoothly and easily and may interfere with its performing the functions intended.

All vertical oil cups should have a piece of clean waste inserted to retain the oil and keep out the dust and dirt. See that every belt is properly laced and of the right tension. If too tight, instead of over straining it in putting it on, it is much the better plan to relieve it a little by letting out the lacing, and then take it up when the belt has 
stretched. If they are dry and hard, a little neatsfoot oil, in which a very little resin has been dissolved, will help to soften them and add to the life of the belt. See that no rivet heads project through the lagging on the pulleys for they cut the surface of the belt as it passes over them. See that every nut and bolt in the entire machine is tight and in its proper position.

If the frame of the machine is warped, try to get it in line. Any worn teeth should be replaced with new ones. Straw rakes and raddles should be examined with care and put in good condition. If wooden trucks are used see that tires are tight, if iron, see that every spoke is screwed up to its proper tension.

The tool box is quite an important adjunct to a well equipped outfit. It should be provided with the necessary tools such as hammers, wrenches, chisels, files, etc., together with assorted sizes of bolts, screws, rivets and nails, that would be liable to be needed at any time. Much valuable time may be saved by being able to replace at any moment such small parts that might be lost or broken. The box should be well covered to exclude all dirt and chaff so that any article can be found at a moment's notice. Each tool and piece should have its place in the tool box and be kept there, then it can be found at any time, and will be missed from its place as soon as mislaid or lost.

If the machine is a new one everything should be put in its proper place and the machine gone over and all nuts tightened, leaving each nut standing square with the piece upon which it rests. This will give a symmetrical and workman-like look, and any time afterwards if a nut should start to turn and loosen, the eye having become accustomed to seeing the nuts stand square will detect the change, and it can be again tightened before being lost

The machine should be run empty for a time before having the crew assembled, to see that everything is in working order. New belts after running a short time usually stretch and need to be cut and tightened. See that all cinders and dirt are removed from the boxes and pack them with waste to retain the oil and exclude dirt. 


\section{THE CREW.}

The duty of the Manager is to have charge of the machine and crew and see that everything is operating properly, arrange the work so it may be done in the most expeditious manner, economize time and expense to accomplish the most with the least outlay of labor; look after the welfare and comfort of the crew, and see that each one performs the tasks assigned him. Much depends upon him for the success of the machine.

To make the machine work properiy and do its best it is necessary that each man should perform his part and it belongs to the Mlanager to see that this is done and should be entirely under his control. There is no place where a head and leader is more essential than around a threshing machine. The Manager should assert his rights in a firm and mild manner, never lose his temper and show anger or abuse any one, nor permit any of the crew to abuse each other. It is very demoralizing if there is one or more among the crew who is a bully and is permitted to exercise his inclinations on his fellow workmen.

The feeders should be sufficiently well acquainted with the machine to be able to work in harmony in order to aid in the successful progress of the work. The usual practice in hand feeding is for each to feed a given time or a given amount of grain when he is relieved by the other feeder. The feeder is the one depended on to regulate the amount being threshed and much depends upon him to make the machine do a good day's work.

The feeding should be even and continuous and as near the same speed at all times as is practicable, that the crew may become accustomed to the amount of grain and straw to be handled, and be able to judge the amount of labor required of them. The motion and working of the machine should be kept well in mind and be noticed and corrected as soon as not right. The motion of the one feeding should be suited to the kind and conditions of the grain being threshed. The more the straw is divided up and spread out the less power is consumed in passing it through the cylinder. This should be borne in mind when horses are furnishing the power as it is generally limited in that case. 
In steam threshing where there is usually more grain being handled and there is plenty of power, the feeder has about enough to do to keep the bundles passing in at the proper speed without much time being spent in spreading them out. The feeding should be as continuous as practicable that the next succeeding bundle should be engaged in the cylinder before the last one has entirely passed through. This will aid the motion and power.

The Band cutters should see that the bands are cut and the bundles passed to the feeder in the most convenient manner to aid him in performing his work. It will greatly assist in the free movement of the bundles to keep the tables free from clinging straws, as the bundles move much easier on the bare table. Care should be exercised in the handling of the knife used to cut the bands, as many a feeder has had his hand cut by inattention or carelessness on the part of the band cutter. Each band cutter should keep his particular side of the machine as he can perform the work to better advantage after becoming accustomed to it, than by changing about.

The Pitchers are depended upon to get the grain to the machine in quantities as fast as needed and in a manner to facilitate work. There should be enough pitchers provided so the machine will not have to wait for grain or run partly empty, as it necessitates the remainder of the crew to be partly idle, and curtails the earnings of the machine. They should work harmoniously with the end in view to make the day's work as profitable as possible for the machine.

It is better practice for each man to keep his particular position on his own side of the machine during the time he is with it. He then becomes accustomed to moving the bundles in a certain way on that side, while on the other side the pasition would be reversed. The work will be perforned much more expeditiously and with greater ease as the muscles become accustomed and hardened to a certain movement of the pitch fork.

The Straw Crew are to take care of the straw as fast as delivered from the carrier.

It will be found to be as easy to form and build a good symmetrical stack as to simply push the straw back, without any reference to the form of the pile.

The straw will have to be moved a less distance to commence the 
stack well up toward the machine so the stacker will drop the straw nearer in the center of the stack, than if commenced back so far that the stacker comes only to the edge, as then it will have to be moved clear across the distance of the stack. To keep well the center should be tramped more. The outside portion will then settle more causing the straws to incline downward at the out side making a better watershed. This it will be observed is the case when the stacker delivers the straw to the center of the stack, as the straw men will then naturally stand there to move the straw to either side.

\section{THE ENGINE.}

The Engine is a secondary consideration as it is only a means to accomplish an end, that of making the separator run. It is the separator that does the real work of threshing and cleaning the grain, which is the object sought for.

The Power to run the separator is necessary and should not be entirely forgotten. It should be kept in good repair and will well repay for the necessary time expended in keeping it so.

The power is imparted to the steam engine by the expansion of water, which when heated passes off into vapor called steam. The office of the boiler is to generate this steam.

Heat is simply a vibratory motion of the molecules of the body through which it passes. This heat is produced in the fire box of the boiler by the union of two or more gases, viz., that produced from the fuel called carbonous gas and the oxygen supplied by the air. When an atom of carbon and oxygen come near each other they unite and form carbonic acid gas. The motion produced in the process is the source of heat, the union is called fire. To produce the best results the gases should be united in about the right proportion. If too much air is admitted for the amount of gas coming from the fuel, the result will be a loss of heat by its being absorbed by the air. Or if not enough air is admitted to the fire box to properly unite with the carbon, 
the result is that the gas of the fuel passes off without being consumed and is thus wasted. It is necessary then that the proper amount of air should be admitted, and this should be thoroughly mixed with the gases of the fuel while in the intense heat of the fire or the union will not take place properly.

The natural draft of an engine is increased by the use of the nozzle at the end of the exhaust. The smaller the nozzle the stronger the draught. This nozzle should not be smaller than is necessary, as it causes back pressure, reducing the power of the engine.

The cylinder and piston should be tested occasionally to see if the piston rings are leaking. This can be done by putting the engine off center and chaining the fly wheel so it cannot revolve, and open the throttle carefully. If the cylinder cock in the opposite end of the cylinder to that which steam is entering be opened and steam escapes through it very much, it indicates that the rings or valve is leaking. The steam will also escape through the exhaust nozzle if leaking, and should be remedied.

Like the separator, the engine should be made to stand still upon its trucks while at work, and set back enough to tighten the belt sufficiently to keep it from slipping.

The governor of an engine should be in good working order at all times, and adjusted to give the required speed to the separator whether working hard or running light and the throttle left wide open while at work. It is poor practice to try to regulate the speed or power by partly opening the throttle as when the separator is being fed heavily is the time more steam is required to keep up the motion.

The packing around the governor stem should not be so tight as to prevent it from working up and down as the change of speed occurs.

But in some high speed governors that are inclined to dance when the engine is working light, if the packing be screwed down lightly to cause a little friction on the stem, it will make the engine run smoother.

The governor belt should be tight enough to run the governor at the required speed without slipping.

As uniform a fire should be maintained as possible, as building a hot fire and then letting it cool down somewhat is very hard on the flues and firebox. Heat always causes iron to expand. With a hot 
fire going the flues become longer, due to expansion. Then when the fire cools down, the flues contract and become shorter. If this practice is continued from day to day, the expanding and contracting process will tend to work the flues loose in the flue sheet, and cause them to leak.

\section{Setting The Machine.}

Some put great stress on how their separator is set when ready to work, though they can not always tell just why it must be that particular way. Some set one end a little high, others would set the same machine differently and contend it was nearer right. These ideas are usually gotten in threshing some particular setting which went extra good other conditions being favorable, and not entirely understanding the features and functions of all the parts of the machine, they conceived the notion that it must be set just so, or no go. It is not to be understood by this that it makes no difference as to how the machine is set, but it would be hard to explain the reasons why an incheither way would make any material difference. However if a man understands his machine perfectly, and has well founded reasons for being so exact, he should continue to be so.

Often much valuable time is consumed in getting the machine leveled to an exact angle and after it has run a few minutes if on soft ground or if the dirt has been partly removed from some of the wheels it settles out of position; but the Operator seldom knows it as he does not use the level again after starting up.

Sometimes with the vibrating rack if the straw is loose and fluffy and the stroke is not sufficiently long and sharp to work it back fast enough to separate well, the separator may be lowered at the rear end to advantage as the straw will work off a little faster than if higher.

The separator should be near enough level sideways to prevent the grain from shaking down to one side of the sieves. If the grain is blowing over on one side, it can sometimes be remedied by lowering that side of the machine, causing more grain to pass there thus partly retarding the blast. 
When traction engines are used to draw the separator, a good practice that saves some time in setting and leveling the machine is to draw the separator near to the place and then prepare the resting place just in front of the trucks by either digging or blocking up as the case may be, (leaving the engine coupled on), then draw the separator in place. If correct uncouple, if not back up and make the necessary adjustment and again set it in place with the engine. This takes but a moment the separator being quickly and easily moved with the engine. If left to be done by hand and the ground should be uneven, it would consume much more time. After the engine and separator men have become accustomed to this plan, but little time will be used in getting the machine in position, even in difficult places.

As soon as the engine is uncoupled and starts away the drive belt should be taken out at once and put in position to designate to the engineer where to place the engine. The particular spot may be marked by a bunch of straw or in any convenient way, and the end of the belt laid aside to permit the engine to come to place without the engineer having left the foot board. As soon as the engine is in proper position help should be there and the main belt run on; in the mean time the pitchers have ascended the stacks, the Manager gives the word, the machine starts rolling in a time so short it would surprise an on looker that had been used to the old "take your time" sort of way in setting.

If the crew gets in the habit of visiting and swapping stories at each setting, it is so much more comfortable a way of putting in an hour, that the loss of time is not noticed. The best results cannot be attained unless the whole crew work in harmony and are willing to carry out the instructions of the Manager. Very much depends on him to keep everything coming in its proper place without jar or friction.

\section{MOVING.}

During a fall's run from one fourth to one half of the time is consumed in moving and setting. Some sections of the country require more than others, and some threshermen's work is more compact and closer together than others. A thresherman should study well to attain the most expeditious plan to tear up and move, as nothing is being 
earned while the golden stream is not running. All should work together to clean up and be off to the next setting without delay. The Manager and Engineer should see that everything possible is loaded, the horses if used, gotten ready to hitch on, so that as soon as the belt is thrown off and rolled up everything is ready to go.

The ronte to the next setting should have been looked up by the Manager and he should see that the road is clear, that no stops need be made while in transit.

If convenient the setting should have been visited and he should see that it is properly cleared of all rubbish or stones that may be there, and decide which way the straw is to be thrown, as it often saves much valuable time to the machine by discussing the question beforehand.

While on the road it will often save time for the Manager to be ahead and designate to the engineer or drivers, the road to be taken. If an unsafe bridge or other obstruction is to be encountered, the Manager should know it, that the course to be taken may be decided upon without causing any delay to the machine.

A little thought and study beforehand spent in planning the details, will save much time in executing the work.

A place should be provided for every article to be carried along. Each oil can, spade, bar and box should have its particular place. Commence to load up before the grain is all cleaned up, putting each piece in its place. By using a regular system the time consumed can be reduced to the minimum, and much labor saved. The engineer will have his engine properly oiled and greased and everything in order and ready to travel at once as soon as the belt is thrown off. Where horse powers are used, each man should have a certain part of the work assigned to him. By following a system and working in unison much time can be saved. But where each one walks around looking to see what the others are doing inuch valuable time is lost.

\section{Wasting Grain.}

There is no place on earth where a kernel of grain looks as large and is of so much value as at the tail end of a machine. To see some hunt and search for them one would think each one a diamond or price- 
less gem. There is no time when a farmer is so careful of his property as right then. Any amount may be wasted by the harvester or in handling the grain, but let him discover a few kernels going into the straw through the machine and he at once looses his reason and imagines ruin stares him in the face. He will show them to the Operator with an autocratic air of "do better or quit."

In a bushel of oats, 32 lbs., there are about 600,000 kernels. In a bushel of wheat, 60 lbs., there are about $1,000,000$ kernels. If he should hold his hand where the grain is wasting fastest for half a minute, and catch ten kernels he would say it was half going in the straw. Let us see Counting 26 days for a month and ro hours for a day it would take him over three months to catch a bushel of wheat. Oh yes, he says but he only held his hand under a small part of the falling chaff. Well suppose the machine was 52 inches wide and his hand only 2 inches, and the grain wasting equally across the entire width, it would then take three days at the same rate for enough kernels to pass to fill a bushel measure.

In order to waste 5 bushels in a day of 10 hours run, there would have to be $\mathrm{I} 38$ kernels escape every second or 8,240 every minute. It is very deceiving when the quantity of grain comes to be measured by the kernel. While most threshers are willing to do all in their power to save the grain for their customers, the farmer should remember that absolute perfection is impossible and that the actual waste is but very small as compared to the amount threshed.

It is difficult to state what per cent. a machine may waste and still be doing reasonably good work. There have been several tests made to determine this but the conditions varied so that there are scarcely two reports alike. In ordinary threshing when the conditions are not unfavorable and the machine not being over crowded it should not waste more than ${ }_{3}^{1}$ of 1 per cent this will be only a little over 3 bushels per thousand. Calling 10 hours a day and threshing 1, 0oo bushels and wasting 3 bushels it would necessitate losing what would lay on the palm of the hand every 15 seconds, not a very long space of time only a quarter of a minute. This would show very plain, and the machine would appear to be wasting very fast. If the kernels are still in the head unthreshed the waste may be in much larger proportion; a kernel in every head or two soon counts up. 


\section{Notes.}

The air has a pressure of between 14 and 15 pounds to the square inch and varies slightly at different times and places. This pressure is in all directions pressing as hard on the under side of an object as on the upper side.

A cubic yard of air weighs nearly 2 pounds. Air will expand and contract according to the pressure it is subjected to. Thus if a cubic yard at a pressure of 15 pounds per square inch weighs 2 pounds, a cubic yard at a pressure of 30 pounds per square inch would weigh 4 pounds, at $7 \mathrm{I} / 2$ pounds pressure it would only weigh I pound. This also shows that to double the pressure reduces the bulk one half.

A MOVING COLUMN OF AIR DOES NOT EXERT IULL ATMOSPHERIC PRESSURE AT RIGHT ANGLES TO ITS LINE OF MOTION. ITS LATERAI, I'RESSURE DELREASES IN PROPORTION AS THE SPEEI) INCREASES.

The above law largely explains the difficulty experienced in getting the blast equally distributed through all parts of the sieves, as the blast makes many whirls and turns in obedience to these lateral pressures as it comes from the fan.

Pulleys or band wheels are made a little fuller or larger in the center to cause the belt to stay on and not run to one side of the pulley.

If two shafts on which are pulleys are nearer together at one end, the belt will tend to travel towards the ends nearest together.

If two shafts run parallel on which are pulleys that are larger or fuller on one side, the belt will tend to travel toward the larger side of the pulley.

Two shafts are parailel when their centers are the same distance apart throughout their entire length.

When threshing, the engine runs the separator by pulling on the belt and requires a steady pull of 200 to $400 \mathrm{lbs}$, according to the size of the machine, the condition of the grain, the attachments on the separator and the size of the cylinder pulley. 
The life of a separator should be from 12 to 15 years while some have been in active use 20 or even 25 years. Many discard machines long before they are worn out. Because the paint has become dull or a few of the boxes worn out is no reason why an otherwise good separator should be stood aside and a new one purchased. As long as the frame and trucks are in good condition a separator can with a little expense be kept in condition to do as good work as when new. A coat of paint or varnish is inexpensive and adds tone and beauty as well as lasting qualities.

If dust and chaff are left on the woodwork of a machine in damp or rainy weather the grain mixed with it will sprout and grow causing the varnish and paint to spoil and peel off, as the feeders of the growing roots take up the vegetable matter leaving the wood bare to absorb moisture causing early decay.

If the paint on the separator has become dull from exposure to the weather a coat of good varnish will make it look new again, taking care to remove all grease and dirt before applying it.

The machine is worth what money it will earn. To get the most out of it is the desire of each operator. It will not always earn most by being overcrowded, rather try to run steady and keep going. Nothing is being earned while the machine is idle. The.stream must be kept running. If an hour's time is lost in some useless manner, it can not be made up with profit by overcrowding the machine the remainder of the day.

The cause of failure is as often in the person who is trying to apply a rule, as in the rule itself.

A good governor for a self feeder, to regulate the amount of grain being fed, is the intelligence that controls the fork handle on the stack.

Friction is caused between two surfaces as they are rubbed together, by the unevenness or roughness of the surfaces in contact. No matter how smooth a journal or box may seem to be the surface is dotited all over with minute points or projections with corresponding indentations or depressions between them. When the two metals come in contact, the points or projections of one catch in the depressions of the other and cling fast and break off a part of each other, as they move in revolving. The office of the lubricating oil or grease is to fill in these depressions and form a cushion tending to hold the surfaces of the 
metals apart permitting the small projections to pass each other without coming in contact. Two metals of different kinds usually work together better than metals of the same kind. The arrangement of the points and depressions not being the same they will not settle together as closely as if precisely the same size and distance apart.

Steam in a boiler at 100 lbs., pressure occupies 250 times as much space as the water did from which it was made. At 50 lbs., pressure it occupies 500 times as much space, and at 200 lbs. pressure, 125 times as much.

It is good practice for the Manager or Separator man to go over the entire machine each day and see that each bolt and nut is tight and the belts properly laced, any worn lace being replaced with new. This can be done at odd times and does not take long and is a much better way than letting everything go "clickety clack" until the wheels stop.

If a separator is in good shape there is no reason why it should not be started in the morning and run until noon and from noon till night without stopping for repairs.

After the fall's run is over, the machine should be thoroughly sivept and cleaned of all dust and grease especially the wood and sheet iron work. The dust will retain dampness causing the wood to decay and the sheet metal to rust. A dry shed to house it in is preferable to a damp one.

The Engine should be cleaned of all grease and dirt that will harden if left on. The smoke stack and outside of the boiler should have a coat of linseed oil to prevent rusting.

The boiler should be cleaned of mud and the hand hole plates fastened in again, and all valves and connections kept closed to exclude circulation of air. The boiler will not rust or corrode on the inside if the air is kept excluded, rust being the union of the iron with the oxygen of the air.

If the boiler has formed any scale the most of it will loosen and drop off during the idle season by the unequal expansion of the iron and scale and should be removed before starting up again in the fall. All pipes and valves should be well drained to guard against bursting and straining by freezing.

It is not the machine that does the largest day's work during the fall that earns the most, but is more likely to be the one that does not 
do the smallest day's work that will have the most left after paying all expenses.

Never try to do a large, and don't permit yourself to do a small day's work. It is the steady regular work that counts.

\section{The Whistle.}

The whistle can be made to do service if its use is rightly understood, but it is very poor practice to toot and blow it promiscuously without any plan or method. If all threshermen would adopt and use a prescribed code of signals, those connected with the machine would soon become accustomed to them and understand what they mean.

The less the whistle is used the better, as it scares high spirited horses, excites persons not accustomed to it, and attracts the attention of all within hearing from their work. This time lost would not be very much for one man, but twenty-five or one hundred men losing from one half to one minute a piece is an item which if multiplied often during the fall's run will be of enough magnitude to deserve attention.

\section{CODE OF SIGNALS.}

One long continuous sound is given to attract attention at such times as in the morning or at noon to indicate the working place.

Two long continuous sounds with a short interval between them is to denote the work completed for that day or at that place, as the case may be.

One short sound is to stop.

Two short sounds with a short pause between them, to go ahead or commence work.

Three medium short sounds means to hurry, given to indicate to those hauling grain that the machine is about to wait for them.

One long continuous sound followed by three shorter ones is a signal to the waterman that the supply of water is about exhausted.

A continuous succession of short and rapid sounds denotes fire or other distress and should be responded to by all within hearing of the call. 
No one should ever sound the whistle but the engineer, as one unaccustomed to it can not give the proper expression to the sound.

The stroke of the whistle lever should be full and steady, being well timed. The valve should not be opened too suddenly, but with a clear and steady pull, and closed gradually. The spaces between the sounds should be well timed and of equal length. This will give expression to the sound, pleasing to hear. An old thresherman once said he could tell the character of the engineer by the way he sounded the whistle.

The tone or pitch of a whistle may be changed by screwing the bell up or down. The lower down the sharper the tone will be, and more piercing to the ears of those near by. When the bell is farther up the tone will be of lower pitch and can be heard at a greater distance and is not so distressing to those near by. When set in a position, it should be left so and not changed without good reason, as the people in the neighborhood become accustomed to it and can distinguish whose machine is giving the signals.

Whistles are sometimes made in chimes of two or more tones that are very pleasing to the ear.

\section{Centrifugal Separators.}

There have been many plans and devices tried for the purpose of removing the threshed grain from the straw. At present the efforts seem to be in the direction of centrifugal separators, that is, using centrifugal force to help separate the kernels from the straw. The present plan is to wait for gravity alone to do the work of causing the grain to descend from the straw. This process being naturally slow causes a limit to the capacity of a given sized machine, while in using the centrifugal process the quantity will be limited to the speed of the machine and the amount of straw that can be passed through. There have been quite a number of plans and arrangements tried to accomplish this, the main idea being to have the straw moving in a circular path at the point at which the grain is to be separated from it. The grain having a tendency to move in a straight line will leave the straw at once. If this can be accomplished in a practical way it will greatly reduce the weight and simplify the working parts of the grain separator. 


\section{Gas Engine.}

Gas engines have been used for stationary power for some time, but only of recent years have there been attempts made to use them for threshing purposes. When perfected and brought into general use they will have many advantages.

The power is generated in the gas engine by mixing the vapor of gasoline with air and exploding it in the cylinder. With the proper mixture it has a very high degree of pressure. Some difficulty has been experienced in getting the proper mixture of air with the gas as the proportions have to be about right.

Very heavy balance wheels have been necessary to withstand the sudden shock of the explosion and keep a steady and uniform motion. in some instances this has a tendency to make an engine that is strong enough to run the largest separator successfully, very heavy and unwieldy. The wind and weather have been found to effect them in some instances as the supply of oxygen must be taken from the surrounding atmosphere. But these objections can be overcome and the gas engine made practical for threshing purposes.

\section{How to Become an Expert.}

To become a threshing expert a person should thoroughly understand the principles and details of the machine and become perfectly familiar with all the various parts, their construction and how they perform their work. This knowledge may be gained by close application and study. By becoming interested in the work the mind will store up and retain the necessary knowledge. Enough experience in operating is necessary to recognize at once when each part is performing the function intended and to adjust it if wrong. 
Often when the machine is not working properly the difficulty is where least expected, and the expert will recognize at once where and what the trouble is and know the remedy to put it right without making useless changes or experimenting which takes up valuable time and tries the patience of all concerned. He should know what good threshing is and be able to recognize it at once when he sees it.

The expert should be able to explain the workings of the various parts and their relation to each other in a clear and precise manner. In many cases a clear explanation of the working of a device will show to all its pecularities and points of merit not before understood and cause that to be appreciated which was before condemned. He should bear in mind that all do not understand the construction and working of a machine and not become dissatisfied or find fault with the mistakes of others but as occasion requires try to teach and impart the necessary knowledge.

Many inexperienced threshers have been misled by being made to believe that there are machines built that will simply do perfect work and as fast as can be imagined. They often find this untrue to their sorrow, and it sometimes requires the testimony of an expert to convince them. It would be well for the one called to remember that the thresher is not wholly to blame for his erroneous idea.

\section{Full Crew.}

In some sections of the country a common custom is for the man furnishing the machine to also furnish the full crew and board them, the farmer only taking his grain from the machine as fast as threshed. In this plan the price per bushel is enough more to compensate the extra cost. This method has met with general favor where tried. It is especially profitable to the thresher where the jobs are large and for the farmer whether he has much or little grain to thresh; it certainly has many advantages over the old way. At first there is a slight expense to be met by the thresher in providing suitable tents or shanties on trucks for the crew to sleep in, and for the cook to serve meals in. He must also have dishes, a stove etc., but all these things last during several fall's runs and are more than paid for in the advantages gained. 
The Nanager can have full control of all men connected with the machine, he can get them at work at a regular time each morning, and never has to wait for tardy farm hands. Each man working with the machine knows his place and just what is expected of him, consequently he can do better and more work. An ordinary plain home diet is provided which insures betterhealth for the crew than can be possible under the old boarding around plan. This method saves the farmer the worry and expense of looking up his crew and getting them collected at the proper time, and gives him his time at home during the threshing season instead of being away at his neighbors to help them thresh in return. It also relieves the woman of the house from the very unpleasant task of providing food for so many. The prices vary some in different localities for this plai of threshing but usually are $7 \mathrm{c}$ per bushel for wheat, $5 \mathrm{c}$ for barley, $4 \mathrm{c}$ for oats and $\mathrm{I} 2 \mathrm{c}$ for flax.

\section{A Suggestion.}

A Suggestion as to soliciting threshing. Go about it in a business like way. When you meet the man that has a job you want, ask him for it in a plain practical manner. Assure him that you will do him a good job in a workman like manner and save his grain, and do it in as short a time as is consistent with good work. The subject of price usually comes up at this time and this is the best time to lay the foundation for prompt collections.

Let your rule be one price to every body and the account cash as soon as work is done unless there is reason for an extension Be sure to have this understood at the time, just when and how the account is to be paid. This is business and no one ought to take offense at it. but if nothing is said and the work is done, the parties to the transaction may have entirely different ideas as to the price and time of payment which often leads to difficulties that require some sacrifice to adjust, and the Farmer feeling miffed will resolve to do business with some one else next time, all because the start was not made right.

There is no more reason why a thresherman should wait for his money than anyone else. He has his capital invested and has to pay his help as he goes along. It is usually the thresherman's own fault if he has poor collections, for not being firm and exact. He would better lose a job now and then than to lose the pay after he has done the work. 


\section{TABLE No. 1.}

The following table shows the chemical composition of ordinary firewood.

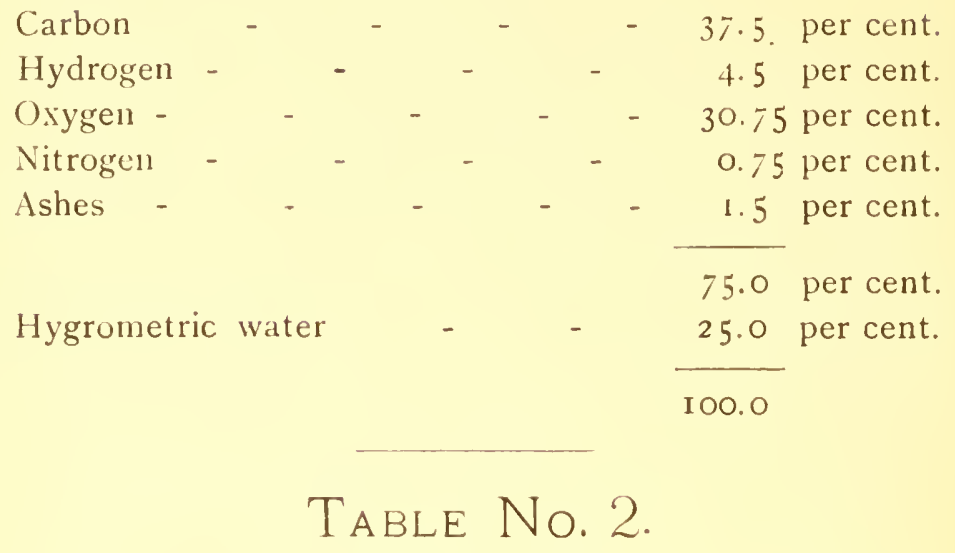

The composition of straw, in its ordinary air-dried condition is about as follows.

\begin{tabular}{|c|c|c|c|c|c|}
\hline & & & $\begin{array}{l}\text { Wheat straw, } \\
\text { Per cent. }\end{array}$ & $\begin{array}{l}\text { Barles straw, } \\
\text { per cent. }\end{array}$ & $\begin{array}{l}\text { Nean, } \\
\text { p'er cent. }\end{array}$ \\
\hline Carbon & - & - & 35.86 & 36.27 & 36.075 \\
\hline Hydrogen & - & & 5.01 & 5.07 & 5. \\
\hline Oxygen & - & - & 37.68 & 38.26 & 38. \\
\hline Nitrogen & - & & .45 & .40 & .425 \\
\hline Ashes & - & - & 5.00 & 4.50 & 4.75 \\
\hline \multirow[t]{2}{*}{ Water } & - & - & 16.00 & 15.50 & 15.75 \\
\hline & & & 100.00 & 100.00 & 100.00 \\
\hline
\end{tabular}

\section{TABle No. 3.}

I Cd hickory or hard maple weighs 4,500 lbs. equals 2,000 lbs. coal. I Cd white oak - - weighs 3,850 lbs, equals I, 7 I I lbs. coal. I Cd beech, red or black oak weighs 3,250 lbs. equals I, $445 \mathrm{lbs}$. coal. I Cd poplar, chestnut, or elm weighs 2,350 lbs. equals I, $044 \mathrm{lbs}$. coal. $1 \mathrm{Cd}$ average pine - $\quad$ - weighs 2,000 lbs. equals $890 \mathrm{lbs}$. coal. I Ton dry straw _ - weighs 2,000 lbs. equals r, i ro lbs. coal, 


\section{TABLE No. 4.}

Total heat evolved by various fuels and their equivalent evaporative power, with the weight of oxygen and volume of air chemically consumed.

\begin{tabular}{|c|c|c|c|c|c|}
\hline \multirow[t]{2}{*}{ FにEL } & $\begin{array}{l}\text { Weight of } \\
\text { (1) xsentin- } \\
\text { sumer per } 16 . \\
\text { of Fuel. }\end{array}$ & \multicolumn{2}{|c|}{$\begin{array}{c}\text { Quantity of Air } \\
\text { romsumeil per lh. } \\
\text { of [tuel. }\end{array}$} & \multirow{2}{*}{$\begin{array}{l}\text { Total Heat ot' } \\
\text { fumbustion } \\
\text { of } 1 \text { Ib of Fute } \\
\text { Itant Inil. }\end{array}$} & \multirow{2}{*}{ 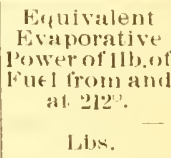 } \\
\hline & Lか心. & I.IS. & $\left(\mathrm{it} f \mathrm{ft}, \mathrm{at}, \mathrm{t}_{2}^{*}\right)$ & & \\
\hline 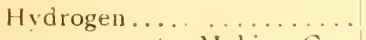 & si.o & 34.15 & 457 & 52000 & $1,2.10$ \\
\hline 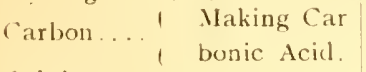 & 2.06 & 11.0 & 152 & $1+500$ & 15.0 \\
\hline Sulphur ............ & I. $.0(3)$ & 4.35 & 57 & 4000 & +17 \\
\hline Coal, iverage dessicated- & $2+5$ & 10.7 & $1+0$ & 17700 & $15 \cdot 22$ \\
\hline Coke, $\quad$ " $\quad$. & $24^{\prime \prime}$ & 10.81 & $1+2$ & I $354^{8}$ & $1+.02$ \\
\hline Eigaice pertect.......... & 2.0 .4 & i. is & (1) & 13104 & $135 \pi$ \\
\hline Asphalt $\ldots \ldots \ldots \ldots \ldots$ & 2.74 & I I. 85 & 15() & 17040 & 17.64 \\
\hline Mood, dessicated......... & 1.40 & 6. Ot) & Sio & 10074 & $11 \cdot 3^{(1)}$ \\
\hline ' $\quad 25$ per cent. moisture & I. .05 & +57 & 110 & 7951 & $\therefore .20$ \\
\hline Straw. $15^{3}+$ percent moist & $0.9 i$ & 426 & 56 & 8147 & $8 .+3$ \\
\hline 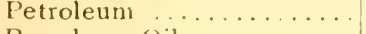 & 3.24 & $14 \cdot 33$ & 150 & 20411 & 21.13 \\
\hline Perroleum Oils ......... & $4 \cdot 12$ & 1793 & 235 & 27531 & 24.50 \\
\hline
\end{tabular}

\section{TABLE No 5.}

\begin{tabular}{|c|c|c|c|c|c|c|c|c|c|c|c|c|c|c|c|}
\hline Silver & - & - & & - & 1000 & Iron & - & - & . & 375 & Boiler & Scale & - & - & $1 x)$ \\
\hline Copper & & - & - & & -850 & Tin - & & - & - & $35^{\circ}$ & Brick & - & & - & 11 \\
\hline Gold & - & & . & - & Sioo & Lead & - & - & - & 200 & Soot - & - & - & - & 10 \\
\hline
\end{tabular}

The above table shows the relative heat conducting power of different substances

The fact that soot and boiler scale are such poor heat conductors shows how essential it is that the fire-box and flues should be kept free from soot and the boiler from scale, to give the action of the fire free access to heat the water. An ordinary Threshing Engine will give from two to four horse-power more, when clean of soot and scale. 


\section{Combustion of Coal}

"When coal is exposed to heat in a furnace, a portion of the carbon and hydrogen, associated in various chemical unions, as hydro-carbons, are volatilized and passed off. At the lowest temperature, naphthaline, resins, and fluids with high boiling points are disengaged: next, at a higher temperature, volatile fluids are disengaged; and still higher, olefiant gas, followed by common gas, light carburetted hydrogen. which continues to be given off after the coal has reached a low red heat. What remains after the distillatory process is over, is coke, which is the fixed or solid carbon of coal, with earthy matter, the ash of the coal.

Taking the fixed carbon, or coke remaining in the furnace after the volatile elements are distilled off, for round numbers at 60 per cent., the following is an approximate summary of the condition of the elements of average coal, after having been decomposed, and prior to entering into combustion:

IOO POINISS ()F AVERAGE COAL IN TIIE FURNALE.

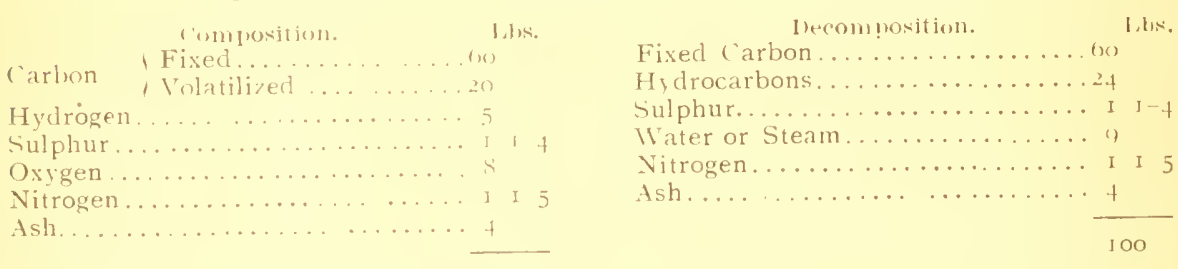

Ahout.................... 100

showing a total useful combustible of $86 \frac{1}{4}$ per cent. of which $26 \frac{1}{4}$ per cent. is volatilized. While the decomposition proceeds, combustion proceeds, and the $26 !$ percent. of volatilized portions, and the 60 per cent. of fixed carbon, successively are burned. 
Table of the Areas and Circumferences of Circles and of the Sides of Squares of the Same Area.

\begin{tabular}{|c|c|c|c|c|c|c|c|}
\hline $\begin{array}{c}D_{\text {iam of of }} \\
\text { circle } \\
\text { in inches. }\end{array}$ & $\begin{array}{c}\text { Circumfereace } \\
\text { of } \\
\text { circle. }\end{array}$ & $\begin{array}{l}\text { Arez of circle } \\
\text { it square ins. }\end{array}$ & $\begin{array}{l}\text { Sides of } S_{z} \cdot \mathrm{c}^{f} \\
\text { same Area } \\
\text { in squaro ins. }\end{array}$ & $\begin{array}{l}\text { Diam. of } \\
\text { Circle } \\
\text { in imohes. }\end{array}$ & $\begin{array}{c}\text { Circumforence } \\
\text { of } \\
\text { circle. }\end{array}$ & $\begin{array}{l}\text { Ares of Circle } \\
\text { iz square ins. }\end{array}$ & $\begin{array}{l}\text { Sidce of eq. of } \\
\text { same area } \\
\text { in square ins. }\end{array}$ \\
\hline 1 & 3.14 & $.7 \$ 5$ & ig & 21 & $6,5.97$ & $3+6 \cdot 3 t)$ & IS 6 I \\
\hline$I_{2}$ & +.71 & I. 7607 & I. 33 & & 67.54 & $36 ; .05$ & 10.05 \\
\hline 2 & 1. 28 & 3.142 & 1.77 & $\cdots$ & 60. I I & 3 ino. 13 & 19.50 \\
\hline $0^{1} 2$ & 7.85 & 4.909 & 2.22 & & 70.68 & 397.61 & 19. 94 \\
\hline 3. & $9 \cdot+2$ & 7.069 & 2.66 & 3 & 72.25 & +15.48 & 20.35 \\
\hline $1 / 2$ & 10.90 & 9.621 & 3.10 & & 73.82 & 433.74 & 20.53 \\
\hline 4 & $12.5^{6}$ & $12 \cdot 5^{66}$ & 3.54 & $2+$ & $75 \cdot 39$ & $45^{2} \cdot 30$ & 21.27 \\
\hline$i^{1} 2$ & 14.13 & I5.90t & 3.99 & ${ }^{1} 2$ & $76.9^{6}$ & 471.44 & $2 \mathrm{I} .7 \mathrm{I}$ \\
\hline 5 & 15.90 & 19.635 & ++4 & & -8.54 & tho.si & 22.10 \\
\hline & 17.27 & $23.75^{5}$ & +.87 & & So. Io & $510.7 \mathrm{I}$ & 22.60 \\
\hline 6 & 18.84 & $28.27+$ & $5 \cdot 32$ & $24 i$ & $R_{I}, 1, k$ & 530.13 & 23.04 \\
\hline$-{ }_{-2}^{12}$ & $20.4^{2}$ & 33.153 & $5 \cdot 7^{6}$ & ${ }^{1} \cdot 2$ & 13.25 & $551 \cdot 55$ & $23 \cdot 4^{\prime \prime}$ \\
\hline & 21.99 & $38 .+85$ & 0.20 & 27 & $s_{4}+s_{2}$ & $572.5^{i}$ & 23.9 .3 \\
\hline $1 / 2$ & $23.5^{61}$ & 44.179 & c. 65 & & 80.34 & 593.90 & $24 \cdot 37$ \\
\hline & 25.13 & 50.260 & 7.09 & 28 & 47.96 & (1) 15.75 & -4.51 \\
\hline $1 / 2$ & 26.70 & $5^{6} \cdot 7+5$ & 7.53 & & 9.53 & $1,37 \cdot 44$ & $25 \cdot 201$ \\
\hline 9 & 28.27 & 63017 & $7 \cdot 9^{x}$ & $2 ! 3$ & () 1.10 & $660 \cdot 52$ & -5.70 \\
\hline $1_{2}$ & $29.8+$ & 70.582 & $8 .+2$ & ${ }_{2}{ }_{2}$ & 02.67 & $13^{3} 3 .+4$ & $2 t) .14$ \\
\hline 10 & $31.4 \mathrm{I}$ & $7^{5} \cdot 54^{\circ}$ & $\therefore s(\theta$ & 30 & 1) 4.24 & 700.86 & 26). 51 \\
\hline $1_{2}^{1}$ & 32.94 & $h(1), 5(70$ & 1).30 & & 35.111 & 30.02 & 27.0 .3 \\
\hline 11 & 34.55 & 95.03 & 9.75 & 31 & $177 \cdot 35$ & 754.77 & $27 \cdot 47$ \\
\hline & 36.12 & 103.87 & IO. IO & & w. & 779.31 & 27.92 \\
\hline 12 & 37.60 & 113.10 & 10.63 & $\because 2$ & I 00.5 & $7 \mathrm{O}_{4} .2 .5$ & 28.36 \\
\hline & 39.27 & 122.72 & 11.05 & & $102: 1$ & $820.5 i$ & 2s tho \\
\hline 13 & to.st & 132.73 & II. 52 & $3: 3$ & 103.6 & $\$ 55 \cdot 30$ & 29.25 \\
\hline & $+2+1$ & I $+3 . I_{4}$ & I I,$g^{\prime \prime}$ & $1 / 2$ & 105.2 & $\operatorname{sis} 1 \ldots+1$ & $29 .(x)$ \\
\hline 14 & $+3 \cdot 96$ & I53.9. & $12 .+1$ & 34 & $106 .$. & $107 \quad 122$ & 30.13 \\
\hline & $45 \cdot 55$ & 16513 & 12.85 & & 105.3 & $13+. s 2$ & 30.57 \\
\hline 15 & $47 \quad 12$ & $17^{6} \cdot 7^{2}$ & I 3.29 & 35 & 109.13 & 962.11 & 31.02 \\
\hline & $4^{8} .69$ & I 88.69 & 13.74 & ${ }^{1}=$ & III. 5 & chisu. iso & $3^{1} \cdot 4^{\prime \prime}$ \\
\hline 16 & $50.26)$ & 201.001 & It. It & 36 & JI3.0 & 1017.88 & 31.00 \\
\hline $1 / 2$ & 51.83 & 213.83 & $1+.612$ & $1 / 2$ & $11+.11$ & 1046.35 & 32.35 \\
\hline 17 & $53 \cdot 40$ & 226.96 & 15.07 & 37 & I 10.2 & 1075.21 & 32.717 \\
\hline $1 / 2$ & $5+.97$ & $240.5 \%$ & $15.5 \mathrm{I}$ & $1 / 2$ & 117.8 & $\mathrm{IIO}_{4} \cdot 47$ & 33.23 \\
\hline 18 & 56.54 & $25+.47$ & I 5.95 & 38 & $119 \cdot 3$ & II 34.12 & 33.6 .5 \\
\hline $1 / 2$ & $5^{8.11}$ & 268.80 & 16.40 & ${ }^{1}{ }_{2}$ & 120.4 & $i(t)+.16$ & 34.12 \\
\hline $1 !$ & $59.1 \%$ & 283.53 & 16.84 & $\therefore !$ & 122.5 & $119+.51)$ & $34 \cdot 5^{\prime \prime}$ \\
\hline $1_{2}$ & $5 \mathrm{I} .26$ & 298.65 & 17.28 & ${ }^{1} \cdot 2$ & 124.0 & 1225.42 & 35.01 \\
\hline 20 & 62.83 & $31+.16$ & 1772 & 40 & 125.6 & 1256.64 & $35 \cdot+5$ \\
\hline$/ 2$ & 64.40 & 330.06 & 18.17 & & 127.2 & I. 285.25 & 35.80 \\
\hline
\end{tabular}




\section{INDEX.}

AIR

PAGE.

86

Moving Column of. ......................... 86

BabBitting Boxes............................. 7475

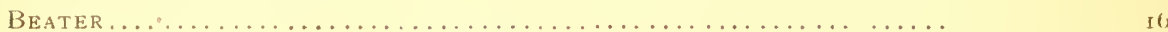

Position of .......................... 10,63,64

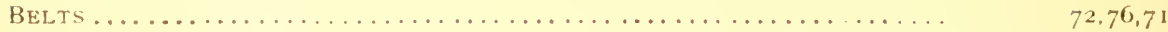

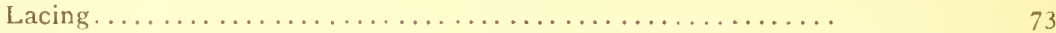

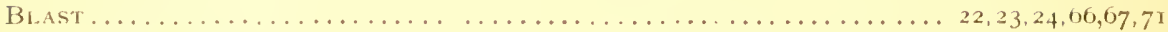

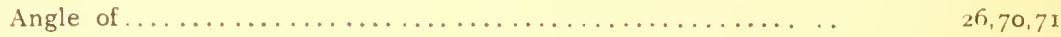

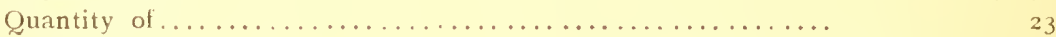

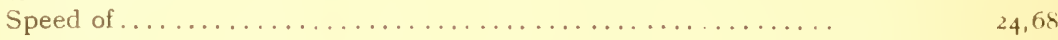

Strength of ... . . . . . . . . 2 2,23,24,68

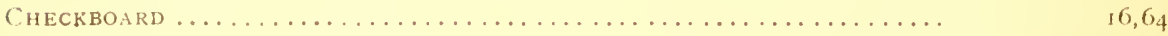

Concales. .................................... 12,67

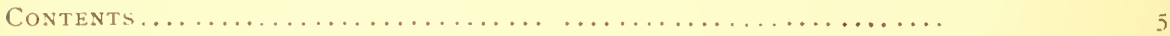

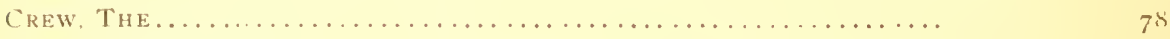

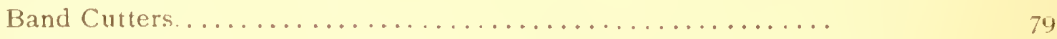

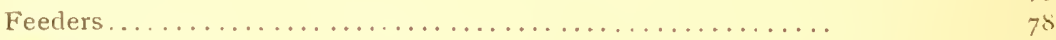

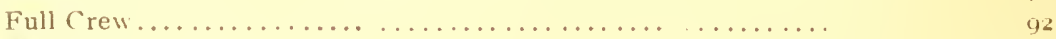

Manager............................................

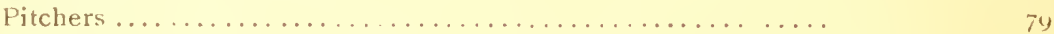

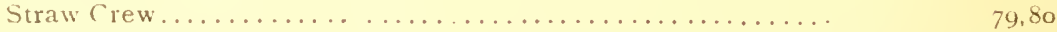

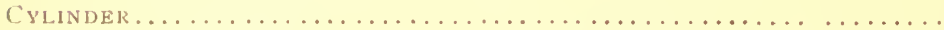
$4,65,67$

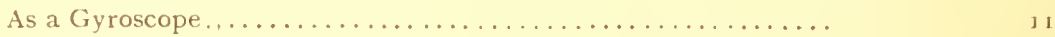

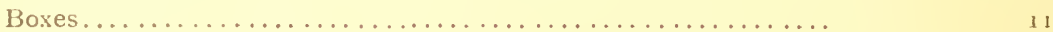

In Balance................................. 9.10,62

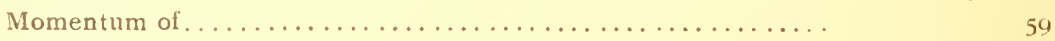

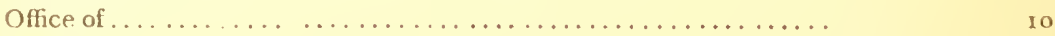

speed of $\ldots \ldots \ldots \ldots \ldots \ldots \ldots \ldots \ldots \ldots \ldots \ldots \ldots \ldots \ldots \ldots \ldots \ldots \ldots \ldots \ldots$ 
ENGINE, ГHE

So. 80,85

FANS.

22,67

Operation

68,69

Overblast

To Test.

1) 9.70

Underblast.

FEED BOARD

FeEdincr.

FULL CREW

92,93

Gas ENGINE

Getting REAdy.

A Kernel of

Grates.

Handling The Grain.

HEAT

How tO BECOME AN ExPERT

8o, 81,82

INTRODUCTION

LACING A BELT

LUBRICATION.

MACHINE, ThE

Care of ....

Earnings of

Is Worth,

Setting

Movisg

83.84

Notes.

OPERATION

PREFACE .

Pulley's

RACK

$$
\text { Motion of }
$$

RADDLE

SELF FEEDERS

Cuts of.

Governors

Shaprating Devices.

Capacity of

Cuts of

SEPARATION.

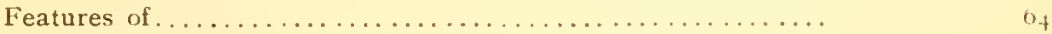

Separator, THE

Care of

Centrifugal

Life of . 
Setting

speed of.

Should Siand sitil.

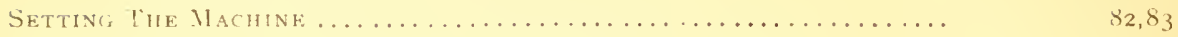

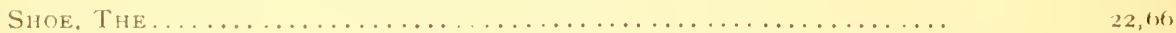

Adjustment of .................................... 1,80

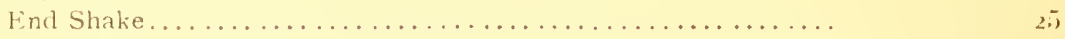

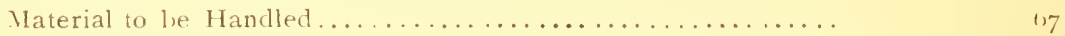

Motion of . . . . . . . . . . . . . 2., 20, 1,6

Side Shake. ..............................

SIEVE. ...................................

Aclapted to the Work. ...................... 22,70.71

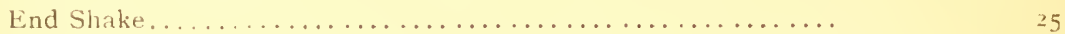

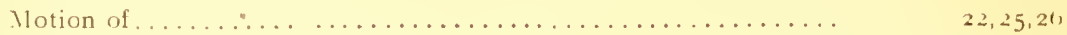

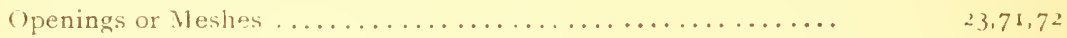

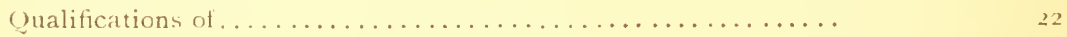

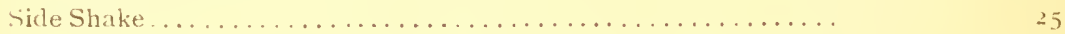

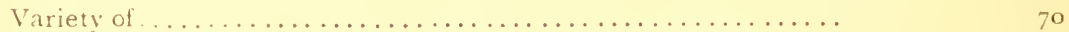

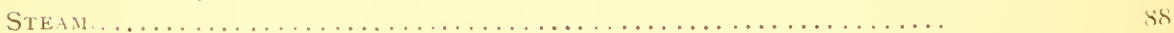

SugGestion, A ..............................

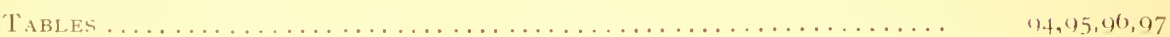

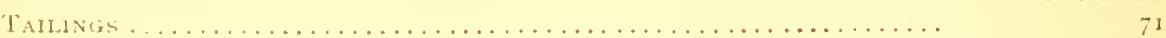

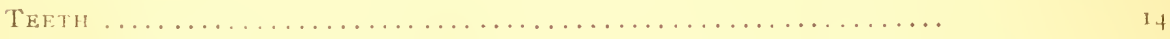

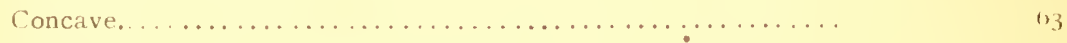

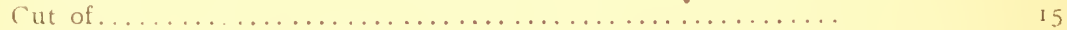

Cylinter............................... 10,62

Worn.................................. 112

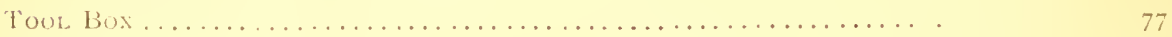

WHWTLE $\ldots \ldots \ldots \ldots \ldots \ldots \ldots \ldots \ldots \ldots \ldots \ldots \ldots \ldots \ldots \ldots \ldots \ldots \ldots$

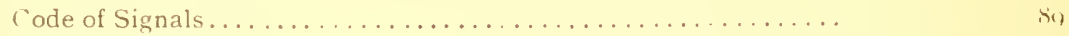

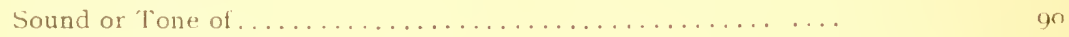

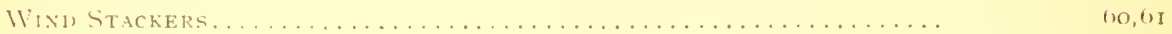




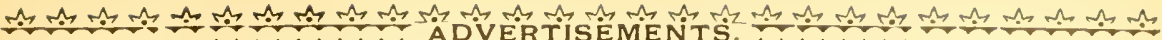

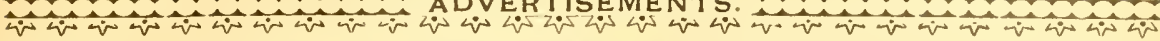

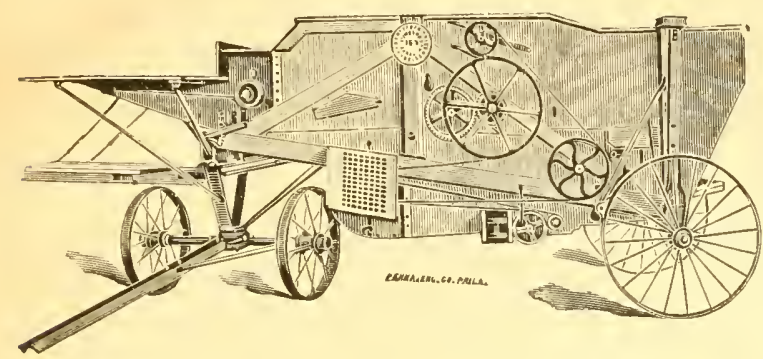

\section{FRICK COMPANY}

Eclipse

\section{Machinery.}

All Of The Highest Grade.

The "Eclipse" Traction Engine with Friction Clutch, mounted on Independent Steel Frame Work, and with many special features.

The "Landis-Eclipse" Separator, Wind stackers and attachments, making the best and most modern machine ever offered.

Also Eclipse Saw Mills, Portable Engines, Stationery Engines, Boilers, Ice and Refrigerating Machinery. For catalogue of particulars address

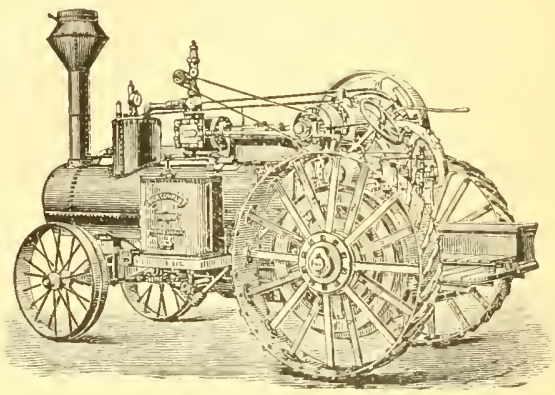

FRICK COMPANY, Waynesboro, Franklin Co., Pa. 


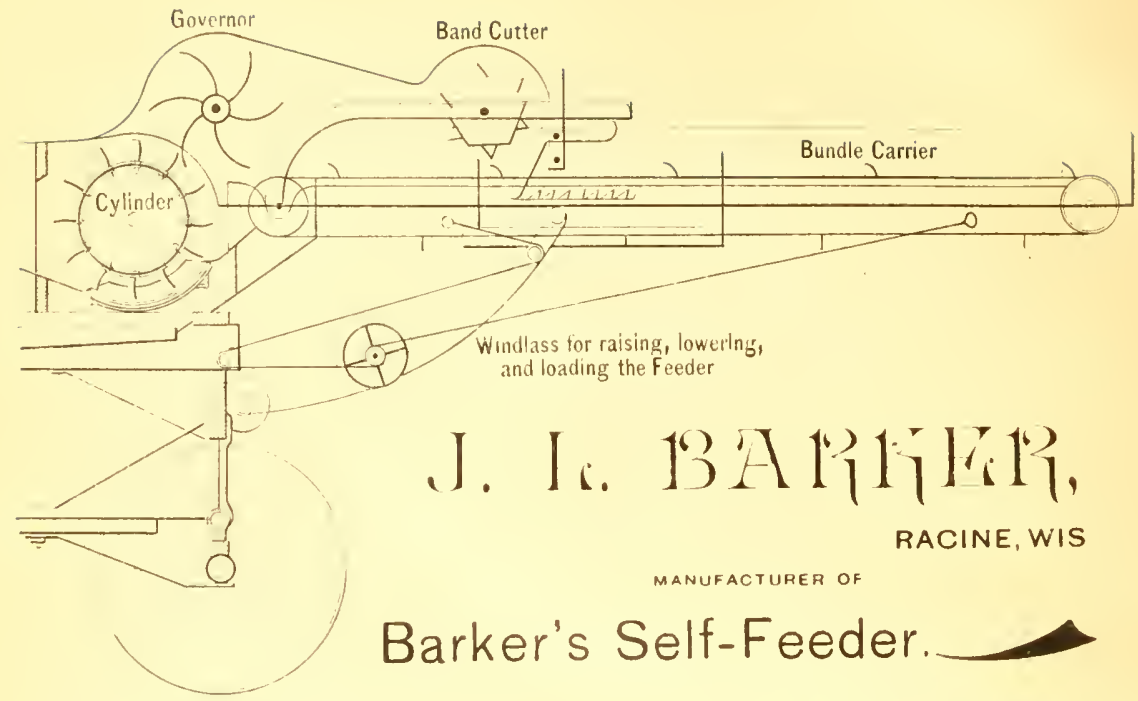

The 24 double edge knives on the band cutter cut every band.

The corners of the six-sided band cutter knock the top half of the bundle into the Governor ahead of the bottom half and then tear the bottom half all to pieces.

The long curved fingers of the slowly revolving Governor prevent wet grain slugging the cylinder. Absolutely the only feeder made that will not slug.

By means of the Windlass and ropes attached to the hollow iron leys, the feeder can be instantly raised to get at the concaves, lowered for cleaning up, or loaded on top of separator for moving, in one minute's time.

The Brush under the carrier roller next to the cylinder prevents any littering.

This feeder is used exclusively by Gaar Scott \& Co, and the Nichols \& Shepard Co. Parties desiring feeders to use on Separators made by either of the above firms, are requested to order of them. For use on any other make of separator order of

\section{J. L. BARKER,}


P 








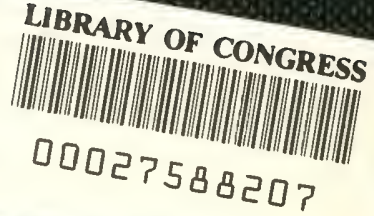

- 